\title{
Community pharmacy personnel interventions for smoking cessation (Review)
}

Carson-Chahhoud KV, Livingstone-Banks J, Sharrad KJ, Kopsaftis Z, Brinn MP, To-A-Nan R, Bond $\mathrm{CM}$

Carson-Chahhoud KV, Livingstone-Banks J, Sharrad KJ, Kopsaftis Z, Brinn MP, To-A-Nan R, Bond CM.

Community pharmacy personnel interventions for smoking cessation.

Cochrane Database of Systematic Reviews 2019, Issue 10. Art. No.: CD003698.

DOI: 10.1002/14651858.CD003698.pub3.

www.cochranelibrary.com 
TABLE OF CONTENTS

ABSTRACT 1

PLAIN LANGUAGE SUMMARY

SUMMARY OF FINDINGS

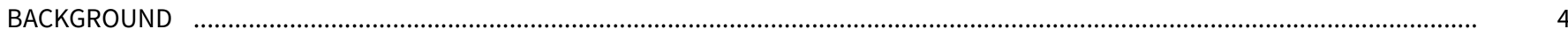

OBJECTIVES

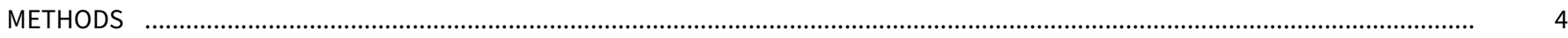

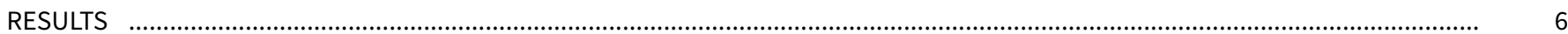

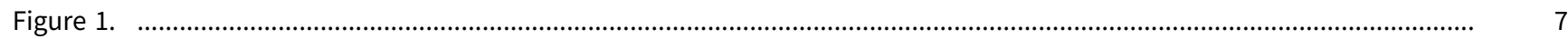

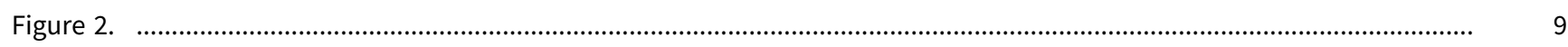

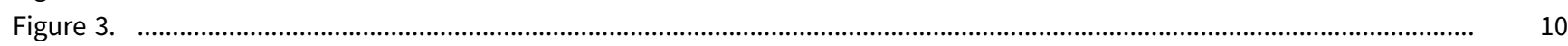

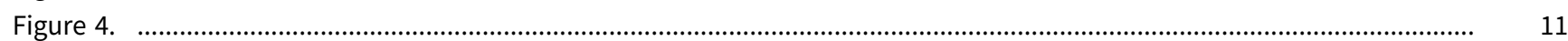

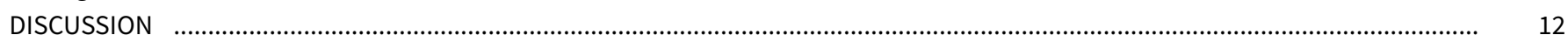

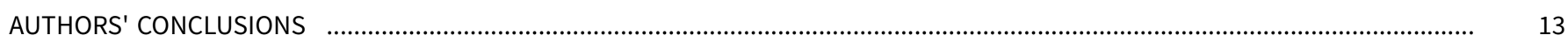

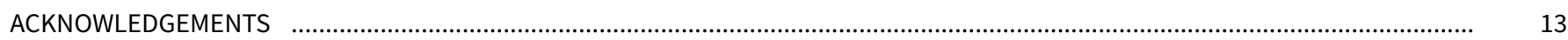

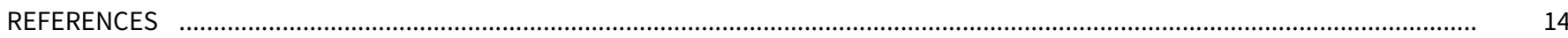

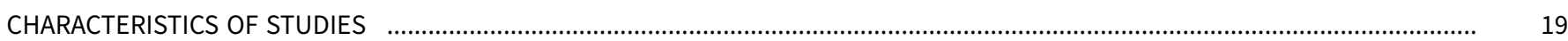

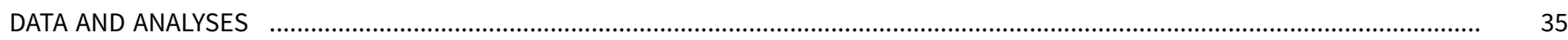

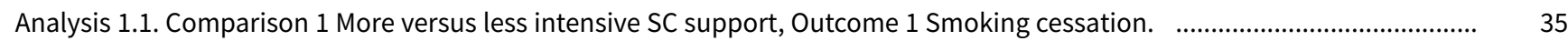

Analysis 2.1. Comparison 2 Face-aging + brief advice versus brief advice alone, Outcome 1 Smoking cessation. ...................... 36

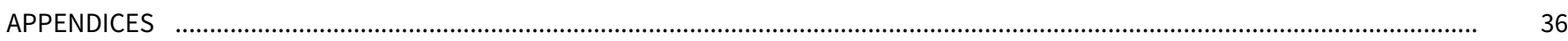

WHAT'S NEW

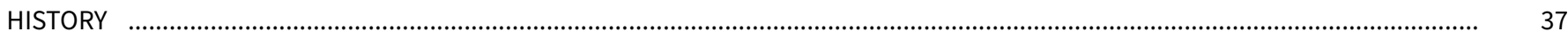

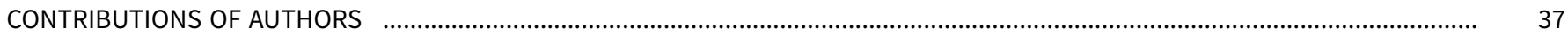

DECLARATIONS OF INTEREST

SOURCES OF SUPPORT

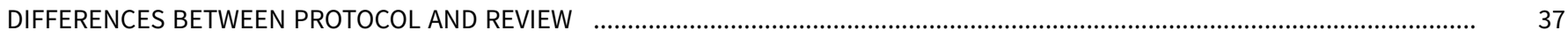

INDEX TERMS 
[Intervention Review]

\section{Community pharmacy personnel interventions for smoking cessation}

Kristin V Carson-Chahhoud ${ }^{1}$, Jonathan Livingstone-Banks², Kelsey J Sharrad ${ }^{1}$, Zoe Kopsaftis ${ }^{3}$, Malcolm P Brinn ${ }^{4}$, Rachada To-A-Nan 5,6 , Christine M Bond7

${ }^{1}$ School of Health Sciences, University of South Australia, Adelaide, Australia. ${ }^{2}$ Nuffield Department of Primary Care Health Sciences, University of Oxford, Oxford, UK. ${ }^{3}$ Respiratory Medicine Unit, The Queen Elizabeth Hospital, Central Adelaide Local Health Network, Adelaide, Australia. ${ }^{4}$ Habit Research Group, School of Public Health, The University of Queensland, Brisbane, Australia. ${ }^{5} \mathrm{School}$ of Pharmacy and Medical Science, The University of South Australia, Adelaide, Australia. ${ }^{6}$ Therapeutics Research Centre, School of Pharmacy and Medical Sciences, The Basil Hetzel Institute for Translational Health Research, Woodville South, Australia. ${ }^{7}$ Division of Applied Health Sciences, University of Aberdeen, Aberdeen, UK

Contact: Kristin V Carson-Chahhoud, School of Health Sciences, University of South Australia, City East Campus, Frome Road, Adelaide, 5001, Australia. kristin.carson-chahhoud@unisa.edu.au.

Editorial group: Cochrane Tobacco Addiction Group.

Publication status and date: New search for studies and content updated (conclusions changed), published in Issue 10, 2019.

Citation: Carson-Chahhoud KV, Livingstone-Banks J, Sharrad KJ, Kopsaftis Z, Brinn MP, To-A-Nan R, Bond CM. Community pharmacy personnel interventions for smoking cessation. Cochrane Database of Systematic Reviews 2019, Issue 10. Art. No.: CD003698. DOI: 10.1002/14651858.CD003698.pub3.

Copyright @ 2019 The Cochrane Collaboration. Published by John Wiley \& Sons, Ltd.

\section{A B S T R A C T}

\section{Background}

Community pharmacists could provide effective smoking cessation treatment because they offer easy access to members of the community. They are well placed to provide both advice on the correct use of smoking cessation products and behavioural support to aid smoking cessation.

\section{Objectives}

To assess the effectiveness of interventions delivered by community pharmacy personnel to assist people to stop smoking, with or without concurrent use of pharmacotherapy.

\section{Search methods}

We searched the Cochrane Tobacco Addiction Group Specialised Register, along with clinicaltrials. gov and the ICTRP, for smoking cessation studies conducted in a community pharmacy setting, using the search terms pharmacist* or pharmacy or pharmacies. Date of the most recent search: January 2019.

\section{Selection criteria}

Randomised controlled trials of interventions delivered by community pharmacy personnel to promote smoking cessation amongst their clients who were smokers, compared with usual pharmacy support or any less intensive programme. The main outcome measure was smoking cessation rates at six months or more after the start of the intervention.

\section{Data collection and analysis}

We used standard methodological procedures expected by Cochrane for study screening, data extraction and management. We conducted a meta-analysis using a Mantel-Haenszel random-effects model to generate risk ratios (RRs) and 95\% confidence intervals (Cls). 


\section{Main results}

We identified seven studies including 1774 participants. We judged three studies to be at high risk of bias and four to be at unclear risk. Each study provided face-to-face behavioural support delivered by pharmacy staff, and required pharmacy personnel training. Typically such programmes comprised support starting before quit day and continuing with weekly appointments for several weeks afterwards. Comparators were either minimal or less intensive behavioural support for smoking cessation, typically comprising a few minutes of oneoff advice on how to quit. Participants in both intervention and control arms received equivalent smoking cessation pharmacotherapy in all but one study. All studies took place in high-income countries, and recruited participants visiting pharmacies. We pooled six studies of 1614 participants and detected a benefit of more intensive behavioural smoking cessation interventions delivered by community pharmacy personnel compared with less intensive cessation interventions at longest follow-up (RR $2.30,95 \% \mathrm{Cl} 1.33$ to $3.97 ; \mathrm{I}^{2}=54 \%$; low-certainty evidence).

\section{Authors' conclusions}

Community pharmacists can provide effective behavioural support to people trying to stop smoking. However, this conclusion is based on low-certainty evidence, limited by risk of bias and imprecision. Further research could change this conclusion.

\section{PLAIN LANGUAGE SUMMARY}

\section{Does quit-smoking support delivered by community pharmacy staff help people to stop smoking?}

\section{Background}

Tobacco smoking is the leading cause of preventable death and disease worldwide. Community pharmacists are respected healthcare professionals who provide easily accessible and convenient healthcare services to their communities, and they are well placed to provide their clients with help to quit smoking. Indeed, many governments recognise community pharmacies as a useful way of delivering many healthcare services. However, we need evidence that these services are effective before we develop them more widely.

\section{Study characteristics}

We searched for relevant studies in January 2019, and found seven studies including 1774 people. Three studies took place in the UK, and one each in Australia, United States, Qatar, and Italy. Each study provided face-to-face behavioural support delivered by pharmacy staff, who received specific training. Studies compared the structured programme to less intensive support to stop smoking.

\section{Key results}

We found evidence that more intensive structured care given by community pharmacy staff probably helps more people to quit smoking than less intensive support to quit.

\section{Quality of the evidence}

We found low-quality evidence that community pharmacy support helps people to quit smoking. Limitations of the evidence came from potential problems with the ways some of the studies were carried out and the low numbers of people who quit smoking across the included studies, which means we are not sure how effective these programmes really are. 
S U M MARY OF FINDINGS

Summary of findings for the main comparison. Community pharmacy personnel interventions compared with standard care or less intensive support for smoking cessation

Community pharmacy personnel interventions compared with standard care or less intensive support for smoking cessation

Patient or population: people who smoke who were motivated to change their smoking behavior

Setting: Community pharmacies (Australia, Italy, Qutar, UK, USA)

Intervention: higher-intensity smoking cessation support delivered by community pharmacy personnel

Comparison: lower-intensity smoking cessation support delivered by community pharmacy personnel

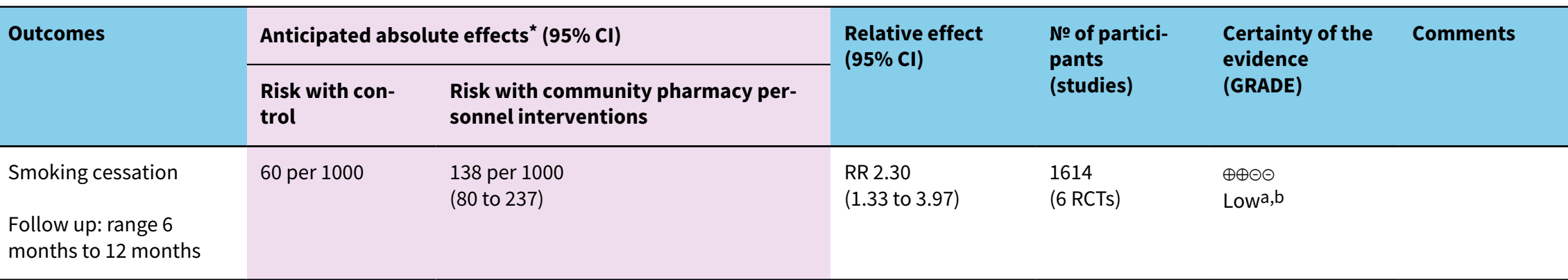

${ }^{*}$ The risk in the intervention group (and its 95\% confidence interval) is based on the assumed risk in the comparison group and the relative effect of the intervention (and its $95 \% \mathrm{Cl}$ ).

Cl: Confidence interval; RR: Risk ratio

\section{GRADE Working Group grades of evidence}

High certainty: We are very confident that the true effect lies close to that of the estimate of the effect

Moderate certainty: We are moderately confident in the effect estimate: The true effect is likely to be close to the estimate of the effect, but there is a possibility that it is substantially different

Low certainty: Our confidence in the effect estimate is limited: The true effect may be substantially different from the estimate of the effect

Very low certainty: We have very little confidence in the effect estimate: The true effect is likely to be substantially different from the estimate of effect

aDowngraded by one level due to risk of bias: we rated all studies at unclear or high risk of bias.

bDowngraded by one level due to imprecision: there were fewer than 300 events across studies. 


\section{B A C K G R O U N D}

\section{Description of the condition}

Tobacco smoking is one of the leading causes of preventable morbidity and mortality worldwide, responsible for the deaths of approximately six million people across the world each year (WHO 2015). Smoking is a major cause of fatal diseases such as cancer, cardiovascular diseases, and stroke (USDHHS 2014). The cost of healthcare services relevant to disorders caused by smoking is high; in 2004 to 2005, it was estimated to cost Australia AUD 31.5 billion in social, health and economic costs, in both prevention and treatment of smoking-induced diseases (Collins 2008). In the USA the annual economic tobacco cost is estimated at USD 289 billion (USDHHS 2014).

\section{Description of the intervention}

Governments and national bodies have long recognised the important role that pharmacists have in the delivery of healthcare services within the community pharmacy setting (Commonwealth of Australia 2018; WHO 1994). Pharmacists are believed to be valuable sources of specialised knowledge for both health professionals and patients alike (WHO 1994). They are easilyreached avenues of reliable information that are often considered more accessible to the general population than general practices (Agomo 2018).

United Kingdom (UK) and USA guidelines (Public Health England 2017; Boutwell 2014 respectively) recommend pharmacists advise on the correct use of nicotine replacement therapy (NRT) at point of sale and provide structured support to aid smoking cessation (West 2000). Evidence suggests that wider provision of smoking cessation through community pharmacies may be: associated with improved cessation (Blenkinsopp 2003; Brown 2016; Saba 2014); is valued by pharmacy customers (Brown 2014; Hudmon 2003; McMillan 2014); is beneficial for health-related quality of life of participants during their cessation attempt (Bauld 2011; Zillich 2002); and is cost-effective (Bauld 2011; Cantor 2015; Csikar 2015; Tran 2002). However, data from randomised trials are needed to examine whether these outcomes are a result of the service.

Although smoking cessation training for pharmacy students has been shown to increase perceived confidence and ability to provide counselling (Brown 2014; Hudmon 2004), the lack of curriculum time and experiential training opportunities still prevent some pharmacy schools from covering this topic adequately (Hudmon 2005). Evidence from trials that these programmes are effective may change this.

\section{How the intervention might work}

Healthcare professionals play a pivotal role in smoking cessation promotion (West 2015), and pharmacists are well placed to provide smoking cessation advice, given their broad interaction with the general community. NRT is available in most pharmacies without prescription and pharmacists may be the only health professional available to offer advice. Other pharmacotherapies, such as varenicline and bupropion, are also supplied largely through pharmacies, and collecting stop-smoking medication represents a key opportunity for smoking cessation support in a community setting. Repeat visits to collect further pharmacotherapy also means that there are multiple opportunities for continued support without the need for follow-up appointments with multiple types of healthcare professionals. Besides potentially increasing access to smoking cessation support, support from pharmacists may help to increase adherence to stop-smoking medications (Hollands 2019), and assist cessation by providing additional behavioural support as an adjunct to pharmacotherapy, which is an effective way to support cessation (Hartmann-Boyce 2019).

\section{Why it is important to do this review}

A systematic review of interventions by community pharmacy personnel is required to provide evidence-based conclusions of their efficacy to inform policy, clinical practice, and future research.

\section{O B JECTIVES}

To assess the effectiveness of interventions delivered by community pharmacy personnel to assist people to stop smoking, with or without concurrent use of pharmacotherapy.

\section{METHODS}

\section{Criteria for considering studies for this review Types of studies}

Randomised controlled trials (RCTs), including cluster-RCTs.

\section{Types of participants}

Community pharmacy clients who were current tobacco smokers and motivated to change their smoking behaviour.

\section{Types of interventions}

Eligible interventions included a behavioural component and were provided by community pharmacy personnel to aid smoking cessation. The intervention may have been delivered by one or more pharmacists or members of pharmacy staff, or both They may have included brief advice or more intensive behavioural therapy, with or without the use of any form of smoking cessation pharmacotherapy. Pharmaceutical trials that compared only the use of a pharmacotherapy with a control in the community pharmacy setting do not fall within the scope of this review.

The comparison intervention could be either no or less intensive behavioural support.

\section{Types of outcome measures}

\section{Primary outcomes}

- Abstinence from smoking six months or more after the start of the intervention. In the event that a study recorded multiple smoking abstinence measures, we used the longest period of follow-up and the strictest definition of abstinence, with preference given to those where biochemical validation occurred.

- Adverse effects

\section{Secondary outcomes}

\section{- Cost effectiveness}

\section{Search methods for identification of studies}

We searched the Cochrane Tobacco Addiction Group Specialised Register of trials. This is derived from regular systematic searches of bibliographic databases including the Cochrane Central Register 
of Controlled trials (CENTRAL), MEDLINE, Embase, and PsycINFO (see the Cochrane Tobacco Addiction Group website for how the Register is populated). At the time of the search on 11 January 2019 , the Register included the results of searches of CENTRAL, issue 1 , 2018; MEDLINE (via OVID) to update 20190108; Embase (via OVID) to week 201902; PsycINFO (via OVID) to update 20181231. Our search strategy is listed in Appendix 1 and Appendix 2.

We also searched online clinical trial registries (clinicaltrials.gov, and the WHO International Clinical Trials Registry Platform) for ongoing and recently completed studies.

\section{Data collection and analysis}

\section{Selection of studies}

Two review authors (from KVCC, JLB, MB, and RT) independently reviewed the literature searches from the title, abstract or descriptors. We excluded all studies that were clearly not RCTs or that clearly did not fit the inclusion criteria. Two review authors then read all other citations in full text, assessing for inclusion based on study design, population, intervention and outcome. We resolved disagreements through discussion and consensus. Had disagreements persisted, we would have resolved them by a third arbiter (CMB). We did not exclude trials on the basis of language or date of publication.

\section{Data extraction and management}

Two review authors (from KVCC, JLB, MB, ZK and KJS) independently extracted data in duplicate from the eligible trials using a standardised data extraction form. We attempted to contact study authors to obtain missing and raw data where required.

\section{Assessment of risk of bias in included studies}

Two review authors (KVCC, JLB) assessed risks of bias in duplicate, in line with recommendations made in the Cochrane Handbook for Systematic Reviews of Interventions (Higgins 2017), and guidance specific to the Cochrane Tobacco Addiction Group. We assessed each eligible study for the following domains: random sequence generation and allocation concealment (selection bias), blinding/objectivity of outcome assessment (detection bias), incomplete outcome data (attrition bias), selective outcome reporting (reporting bias), and other potential bias. For each study, we judged each domain to be at low, high, or unclear risk of bias. We judged studies to be at high risk of detection bias where abstinence was not biochemically validated and the intervention arm received more face-to-face contact than the control arm, as we considered differential misreport a possibility in these cases.

Given that participants and study personnel cannot be blinded in studies of behavioural interventions, and in line with guidance from the Cochrane Tobacco Addiction Group, we did not judge studies based on performance bias.

\section{Measures of treatment effect}

We measured our primary outcome (smoking abstinence) using risk ratios (RRs) with 95\% confidence intervals (Cls). We used the strictest definition of abstinence at longest follow-up, and preferred biochemically validated abstinence where available.

\section{Unit of analysis issues}

Unit of analysis errors occur in studies where the unit of randomisation is clusters (e.g. pharmacies and states), but the unit of analysis is individual participants. This can result in overestimation of the statistical significance of the results by not accounting for the clustering of individuals in the data (Rooney 1996). For studies that did not include adjustments for clustering, we reduced the size of the trial to the effective sample size using the original sample size from each study, divided by a design effect figure, as recommended in the Cochrane Handbook (Higgins 2019). We used a design effect of 1.2.

\section{Dealing with missing data}

Where statistics essential for analysis were missing and could not be calculated from other data, we attempted to contact the authors to obtain data. We assumed that loss of participants that occurred prior to performance of baseline measurements had no effect on the eventual outcome data of the study. We regarded any participants lost to follow-up after the baseline measurement as being continuing smokers.

\section{Assessment of heterogeneity}

We assessed the characteristics of the included studies to determine whether there was sufficient clinical or methodological heterogeneity to preclude meta-analysis. We assessed statistical heterogeneity in our meta-analyses using the $1^{2}$ statistic, interpreted using the following overlapping bands, as given in the Cochrane Handbook (Higgins 2019):

$0 \%$ to $40 \%$ : might not be important;

$30 \%$ to $60 \%$ : may represent moderate heterogeneity;

$50 \%$ to $90 \%$ : may represent substantial heterogeneity;

$75 \%$ to $100 \%$ : considerable heterogeneity.

\section{Assessment of reporting biases}

In the event that we included 10 or more studies in any one comparison, we planned to assess potential reporting biases using a funnel plot. We also assessed reporting bias in individual studies as part of our 'Risk of bias' assessments. We judged studies to be at high risk of reporting bias if the outcomes reported differed from those planned.

\section{Data synthesis}

We conducted a meta-analysis for our primary outcome (smoking abstinence) using a Mantel-Haenszel random-effects model to generate a pooled RR and its $95 \% \mathrm{Cl}$. We used the strictest definition of abstinence at longest follow-up, and preferred biochemicallyvalidated abstinence where available. We used an intention-totreat analysis, and considered participants lost to follow-up as still smoking.

\section{Subgroup analysis and investigation of heterogeneity}

We did not plan or carry out any subgroup analyses.

\section{Sensitivity analysis}

We conducted the following sensitivity analyses:

- removing a study where the provision of pharmacotherapy potentially differed between study arms. This is because between-arm differences in the provision of medications found 
to be effective in helping people to quit smoking would be expected to inflate the effect size attributed to the behavioural intervention being tested.

- removing studies judged to be at a high risk of bias.

\section{'Summary of findings' table}

Following standard Cochrane methods (Schünemann 2017), we created a 'Summary of findings' table for our primary outcome (smoking abstinence), and assessed the certainty of the evidence using the five GRADE considerations (risk of bias, inconsistency, imprecision, indirectness and publication bias).

\section{RES U L T S}

\section{Description of studies}

See Characteristics of included studies and Characteristics of excluded studies.

\section{Results of the search}

The searches for this update found 145 records relating to 126 studies. Of these, we included five new studies in the review, making a total of seven when combined with the two previously included studies. We also found three ongoing studies, and list 37 excluded studies. See Figure 1 for study flow information relating to the most recent update search. We report information about ongoing studies in the Characteristics of ongoing studies tables, and we list reasons for the exclusion of studies in the Characteristics of excluded studies tables. 


\section{Figure 1. Study flow diagram for 2019 update}

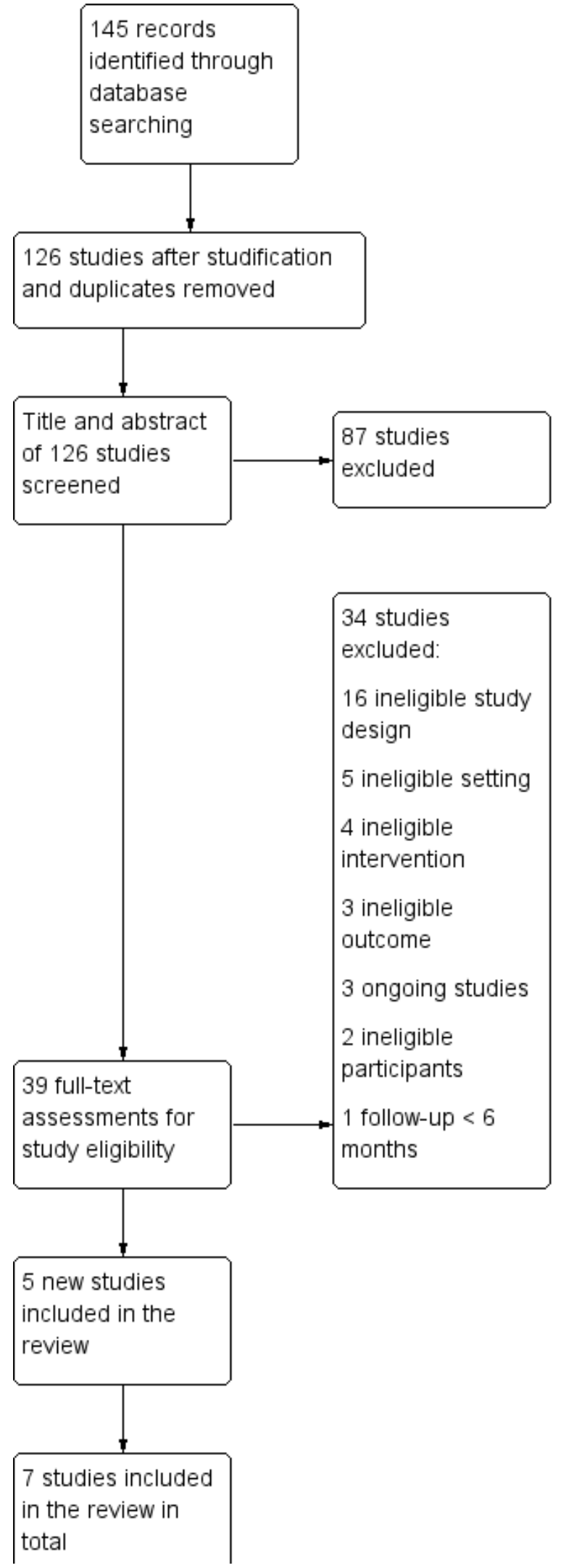


Figure 1. (Continued)

$$
\text { total }
$$

\section{Included studies}

We report details of the seven included and completed studies in the Characteristics of included studies tables.

\section{Study design and settings}

All of the included studies were RCTs. Three studies took place in the UK (Farley 2017; Maguire 2001; Sinclair 1998) and one each in Australia (Burford 2013), USA (Dent 2009), Qatar (El Hajj 2017), and Italy (Caponnetto 2017). All studies were conducted at community pharmacies, either recruiting customers of the pharmacies and randomising them (Burford 2013; Dent 2009; Farley 2017; Maguire 2001), or cluster-randomising using the pharmacists themselves to recruit participants (Caponnetto 2017; El Hajj 2017; Sinclair 1998). All studies were based at multiple pharmacies, except for Dent 2009, which was based at a single pharmacy.

\section{Participant characteristics}

The studies recruited a total of 1774 tobacco smokers attending 186 pharmacies. Sample sizes varied from 68 to 492 participants across studies. Farley 2017 recruited smokers with no intention to quit in the next four weeks, but who did want to reduce their tobacco consumption. All of the other studies recruited smokers who were motivated to quit or visiting a pharmacy in preparation for quitting. All studies recruited adults, with Burford 2013 recruiting 18- to 30year olds specifically. The other studies did not select based on age.

\section{Interventions characteristics}

Each study provided face-to-face interventions delivered by pharmacists (with a pharmacy assistant also involved in Sinclair 1998), and required pharmacy personnel training. Farley 2017 provided two two-hour training workshops for pharmacy personnel; Maguire 2001 provided a three-hour workshop for pharmacists plus one outreach visit; Sinclair 1998 provided a single two-hour workshop for pharmacists and pharmacy assistants; El Hajj 2017 provided literature and a subsequent two-day (8hour day) training workshop for pharmacy staff; Caponnetto 2017 provided a six-hour training session in addition to a three-hour session also provided to pharmacists in the control group. Burford 2013 and Dent 2009 did not report on the nature of training provided.

Each study provided an intervention broadly based on various psychological theories of behaviour change. Farley 2017 used behavioural support counselling to disrupt learnt associations between cues and smoking behaviour; Maguire 2001 used the Pharmacists' Action on Smoking (PAS) scheme (Maguire 1995; Maguire 1996; Maguire 1997); Sinclair 1998 used personalised counselling based on the stage-of-change model; Caponnetto 2017 used the stage-of-change model and motivational interviewing; Burford 2013 used computer software to digitally age photographed images of participants; Dent 2009 used the treatment programme 'Vets without Cigarettes' (Veterans Health Administration 2000), which provides peer support, behavioural strategies and cognitive techniques based on the transtheoretical model of change; El Hajj 2017 developed a training model with the help of various industry experts also based on the transtheoretical model for behaviour change, along with other counselling and behavioural techniques.

The amount of contact intervention group participants received varied between studies. Burford 2013 provided a brief session comparing and discussing the photo-aged images. Dent 2009 provided three two-hour face-to-face sessions in small groups, plus additional follow-up over the phone as necessary. El Hajj 2017 provided four face-to-face sessions over eight weeks. Farley 2017 provided eight face-to-face sessions of approximately 10 minutes length over either four or 16 weeks. Maguire 2001 provided an individual face-to-face session of 10 to 30 minutes, followed by follow-up advice once a week for four weeks, and then once a month for three months. Caponnetto 2017 and Sinclair 1998 did not report the amount of contact provided to participants.

Four studies compared the various support programmes with what they described as 'usual care' (Burford 2013; El Hajj 2017; Maguire 2001; Sinclair 1998). In Burford 2013, El Hajj 2017 and Maguire 2001 'usual care' comprised one-off brief behavioural advice, ranging from two minutes to 10 minutes; in Sinclair 1998, however, 'usual care' was described as anything mandated by UK law, which is the display of health education material at a minimum. Three studies compared the support programmes with other less intensive smoking cessation programmes (Caponnetto 2017; Dent 2009; Farley 2017). Caponnetto 2017 provided pharmacists with a threehour training session to provide support based on US national smoking cessation guidelines; Dent 2009 provided comparator participants with a one-off five- to 10-minute session of advice over the phone, as detailed above, and Farley 2017 provided the same support for smoking reduction as in the intervention group, but in written booklet form rather than as behavioural support.

In all studies, participants had access to pharmacotherapy. Dent 2009 and Maguire 2001 offered pharmacotherapy to participants in both study groups; Farley 2017 prescribed nicotine replacement therapy (NRT) to all participants. Caponnetto 2017 and Sinclair 1998 did not specify, but we presumed that pharmacotherapy was, or could have been, offered to participants in both groups. El Hajj 2017 reported that they 'provided' pharmacotherapy to intervention group participants, but only 'offered' it to control group participants. It is unclear whether this represents a true difference in the treatment provided or just a difference in how the treatment is described. Burford 2013 did not provide or offer pharmacotherapy to participants in either group.

\section{Outcomes}

Farley 2017 reported biochemically-validated prolonged abstinence, with the longest follow-up at six months. Maguire 2001 used self-reported continuous abstinence at three, six and 12 months, with biochemical validation at 12 months. Sinclair 1998 used self-reported continuous abstinence at one, four and nine months. Burford 2013 used self-reported continuous abstinence, with biochemical validation at six months. Dent 2009 used selfreported 30-day or continuous abstinence at six months with 
biochemical validation. El Hajj 2017 used biochemically-validated continuous abstinence at three, six and 12 months. Caponnetto 2017 reported biochemically-validate abstinence at 24 weeks, without specifying a definition of abstinence.

Only one study reported on adverse effects (Dent 2009) and two on cost effectiveness (Burford 2013; Sinclair 1998).

\section{Excluded studies}

Thirty-seven studies appeared relevant from the initial screen but did not meet all the inclusion criteria for further investigation. The main reasons for exclusion were: having no control group; not being an RCT; comparing non-relevant forms of intervention; comparing an intervention not delivered by community pharmacy personnel; including participants that were not community pharmacy clients; not reporting smoking cessation outcomes; and having a follow-up duration less than six months.

\section{Risk of bias in included studies}

Of the seven included studies, we judged none to be at low risk of bias across all domains, three to be at high risk of bias in at least one domain (Burford 2013; Caponnetto 2017; Farley 2017), and the remaining four studies to be at unclear risk of bias (Dent 2009; El Hajj 2017; Maguire 2001; Sinclair 1998). 'Risk of bias' judgements are summarised in Figure 2 and Figure 3. Full details of 'Risk of bias' judgements can be found in the Characteristics of included studies tables.

\section{Figure 2. Risk of bias graph: review authors' judgements about each risk of bias item presented as percentages across all included studies.}

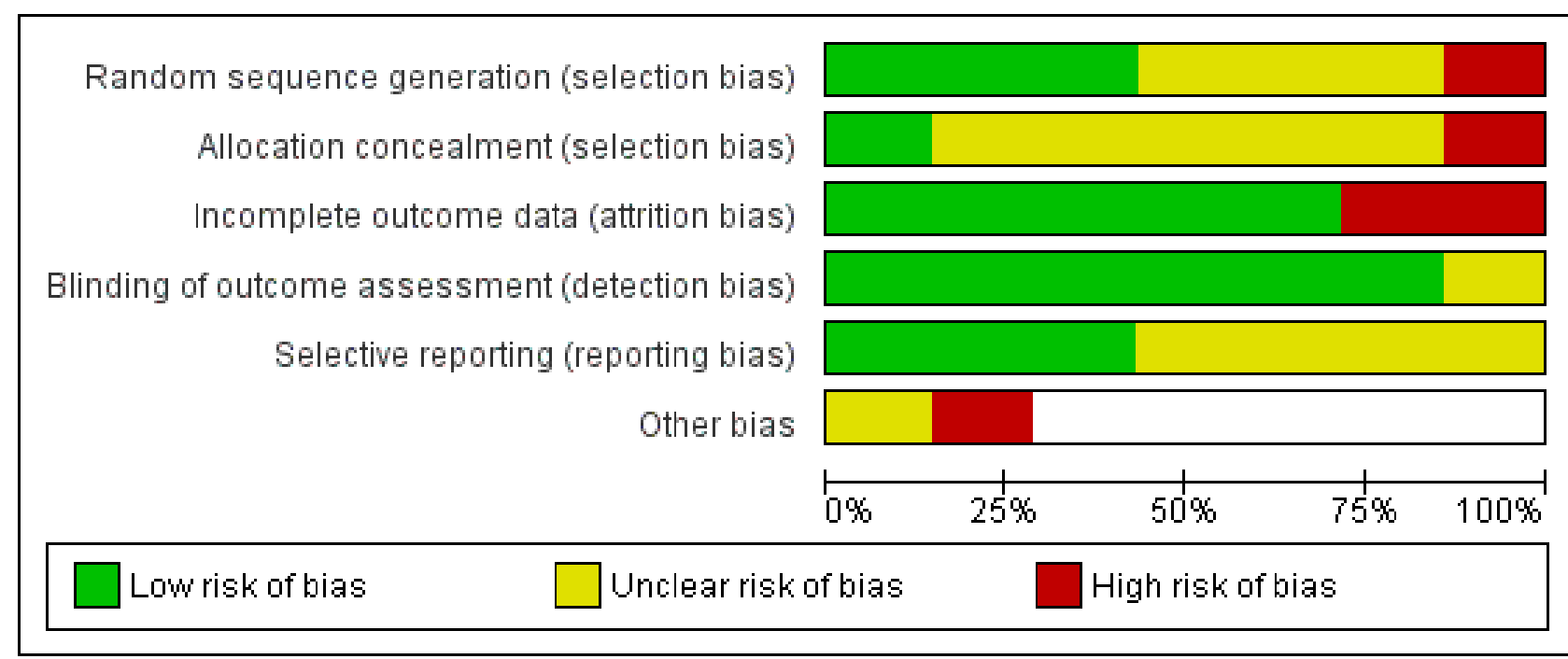


Figure 3. Risk of bias summary: review authors' judgements about each risk of bias item for each included study.

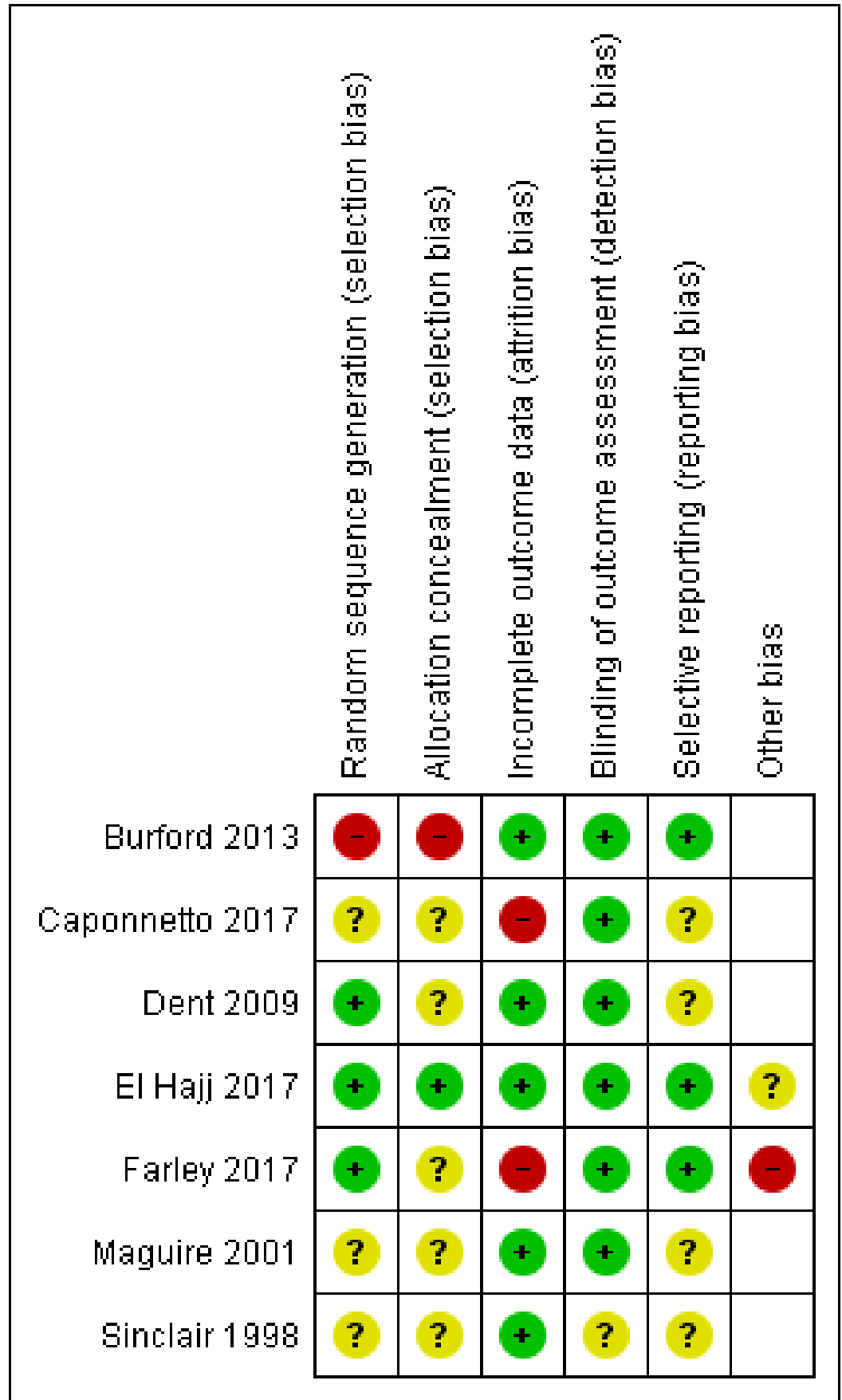

\section{Random sequence generation (selection bias)}

We judged one study to be at high risk of selection bias due to random sequence generation because participant allocation was alternated weekly (Burford 2013), and we judged three studies to be at an unclear risk of bias due to a lack of information (Caponnetto 2017; Maguire 2001; Sinclair 1998). We judged the remaining three studies to be at low risk of bias.

\section{Allocation concealment (selection bias)}

We judged one study to be at high risk of selection bias due to allocation concealment; whilst there was no mention of concealment, we deemed it unlikely, given that the study was not blinded (Burford 2013). We judged one study to be at low risk of bias (El Hajj 2017), and judged the remaining five studies to be at an unclear risk of bias because of a lack of information.

\section{Incomplete outcome data (attrition bias)}

We judged two studies to be at high risk of attrition bias. Caponnetto 2017 suffered significant loss of study clusters, with only 13 of 21 intervention pharmacies and 8 of 21 control pharmacies completing the study; participant follow-up rates were not reported. Farley 2017 also suffered from substantial attrition, 
with follow-up rates differing between study arms. We judged the remaining five studies to be at low risk of bias.

\section{Blinding of outcome assessment (detection bias)}

We judged six studies to be at low risk of detection bias because abstinence was biochemically validated. We judged Sinclair 1998 to be at unclear risk of bias because whilst there was no biochemical validation of abstinence, it was unclear whether contact amounts differed between study arms. We judged no studies to be at high risk of detection bias.

\section{Selective reporting (reporting bias)}

We judged three studies to be at low risk of reporting bias because all outcomes planned in the protocol were reported in the results (Burford 2013; El Hajj 2017; Farley 2017). We judged the remaining four studies to be at unclear risk of bias because we could not find a study protocol. We judged no studies to be at high risk of bias.

\section{Other potential sources of bias}

We judged Farley 2017 to be at high risk of 'other' bias because the study authors reported evidence that pharmacists had not been following the randomisation protocol, and had been routinely providing additional support to participants in the control arm. This may have increased the smoking cessation rates in the comparator group, affecting the magnitude of the overall pooled result. We judged El Hajj 2017 to be at unclear risk of 'other' bias because the study authors reported that it is plausible that the pharmacists, who were overall extremely motivated and enthusiastic, might have inadvertently contaminated the usualcare group by providing extra care, and because it was unclear whether the pharmacotherapy provided in the study arms was matched. The study report suggested that NRT was provided in the intervention arm, but only offered in the control arm. The latter could have inflated the effect of the more intensive behavioural support in the intervention arm.

\section{Effects of interventions}

See: Summary of findings for the main comparison Community pharmacy personnel interventions compared with standard care or less intensive support for smoking cessation

\section{Primary outcomes}

\section{Smoking abstinence at six months}

We pooled six of the seven eligible studies, including 1614 participants. Studies all compared more intensive face-to-face behavioural smoking cessation support with less intensive smoking cessation support. We detected a benefit of the more intensive interventions, with moderate statistical heterogeneity detected: RR $2.30,95 \% \mathrm{Cl} 1.33$ to $3.97 ; \mathrm{I}^{2}=54 \%$; Figure 4; Analysis 1.1.

Figure 4. Forest plot of comparison: 1 More versus less intensive SC support, outcome: 1.1 Smoking cessation.

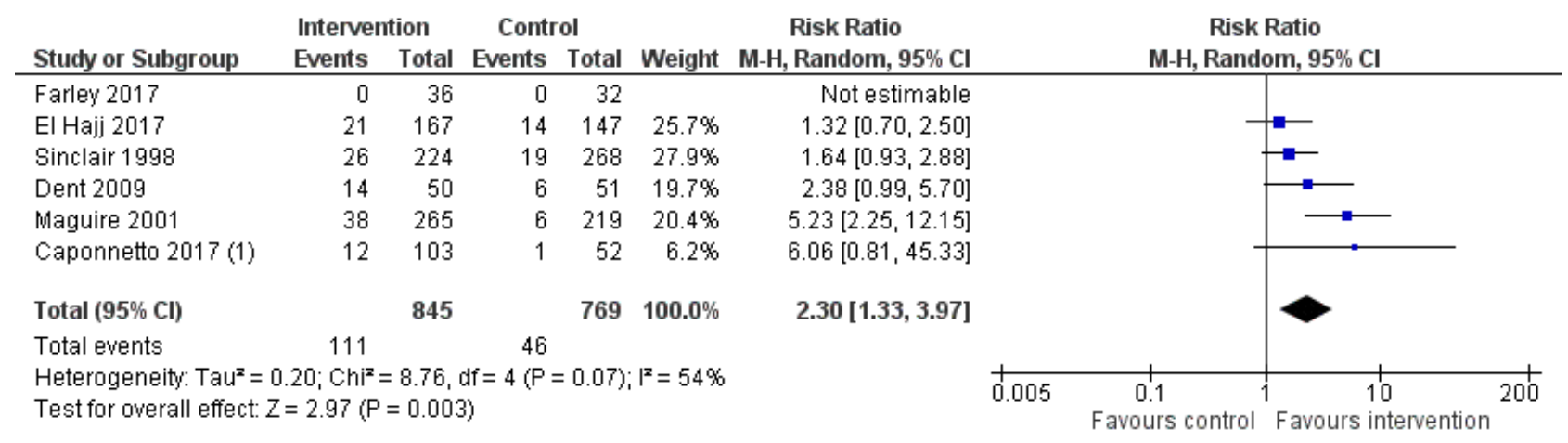

\section{Footnotes}

(1) Divided by a design effect figure of 1.2 to correct for clustering

We conducted a sensitivity analysis to test whether removing the only study that may not have provided identical pharmacotherapy in both study arms had any notable effect on the overall result (El Hajj 2017). The removal of this study did not change the interpretation of the pooled result (RR $2.79,95 \% \mathrm{Cl} 1.46$ to $5.33 ; \mathrm{I}^{2}$ $=51 \%$; 5 studies, 1300 participants).

A sensitivity analysis removing the two studies deemed to be at high risk of bias (Caponnetto 2017; Farley 2017) also resulted in no meaningful change in the pooled effect (RR $2.15,95 \% \mathrm{Cl} 1.22$ to 3.78 ; $1^{2}=60 \%$; 4 studies, 1391 participants).

We did not combine Burford 2013 with the other studies, as we judged it to be clinically heterogeneous. The intervention combined the use of face-aging software with brief smoking cessation advice, compared to brief advice alone This study detected a benefit of the face-aging intervention: RR $11.00,95 \% \mathrm{Cl}$
1.45 to $83.21 ; 160$ participants; Analysis 2.1. However, the $\mathrm{Cl}$ was extremely wide, so this result should be treated with caution.

\section{Adverse effects}

Adverse effects were not among the prespecified outcomes in any of the included studies. However, Dent 2009 reported adverse effects during the intervention period. This study provided a variety of smoking cessation medications, together with the behavioural pharmacy personnel intervention, and adverse effects were attributable to those concomitant medicines. All adverse events from medications were mild. One participant discontinued bupropion hydrochloride because of a rash, and one participant experienced dizziness, possibly related to nicotine toxicity, whilst using the $21 \mathrm{mg}$ nicotine transdermal patch. At final follow-up, participants reported whether or not they experienced any of eight withdrawal symptoms commonly associated with smoking 
cessation, with $96 \%$ of participants reporting at least one withdrawal symptom.

\section{Secondary outcomes}

\section{Cost effectiveness}

Only Burford 2013 and Sinclair 1998 reported data for this outcome. Burford 2013 reported the cost of implementing the intervention as AUD 463.00, or AUD 5.79 per participant. The cost offset from the reduction in healthcare costs from each successful non-smoking participant was AUD 2144.00, resulting in net total savings of AUD 1778.00. We calculated an incremental cost-effectiveness ratio of AUD 46 per additional quitter. The mean cost that participants reported they would be willing to pay for the digital aging service was AUD 20.25, which exceeded the mean cost per participant for delivering the service (AUD 5.79).

Sinclair 1998 reported the overall cost of the intervention as GBP $14,915.76$ compared with control costs of GBP 14,121.13. The intervention resulted in seven more quitters at a cost of GBP 794.63, and they derived incremental cost-effectiveness ratios for the intervention of GBP 300 per person quit and GBP 83 per life year saved.

\section{ISCUSSION}

\section{Summary of main results}

This review includes seven studies assessing the effectiveness of community pharmacy personnel interventions to assist clients with smoking cessation. A meta-analysis of six studies, with 1614 participants, found a statistically and clinically significant benefit in favour of a more intensive community pharmacy intervention when compared with a less intensive control. We judged the evidence contributing to this result to be of low certainty, because of imprecision and risk of bias. We did not include Burford 2013 in the meta-analysis, as the intervention focused on faceaging software combined with brief advice and we deemed it too dissimilar to be pooled. However, this study produced similar findings to the meta-analysed studies with a benefit in favour of the intervention, with the caveat of substantial imprecision. Only one study reported adverse effects during the intervention period (Dent 2009). However, all adverse events were mild and were associated with medication to aid smoking cessation, and were not related directly to the community pharmacy personnel intervention. Only Burford 2013 and Sinclair 1998 reported on cost effectiveness, with results favouring the community pharmacy intervention.

\section{Overall completeness and applicability of evidence}

All of the studies deemed eligible for this review measured and reported on our primary outcome of smoking abstinence. However, other outcomes were only reported in a very small subset of studies, with adverse events only mentioned in one of the seven studies (Dent 2009) and cost effectiveness in two (Burford 2013; Sinclair 1998). Because our inclusion criteria were based on the smoking cessation outcome, there may be evidence on the cost effectiveness of pharmacy personnel interventions that we did not identify and include in this review.

Studies varied in the type and intensity of support offered, but mostly started before quit day and followed up with continued appointments for several weeks afterwards. These support programmes were compared with either minimal or less intensive behavioural support for smoking cessation, typically comprising a few minutes of one-off advice on how to quit. Participants in both the intervention and control arms received equivalent smoking cessation pharmacotherapy in all but one study. This review cannot tell us about the efficacy of pharmacybased support in comparison with no support or relative to other forms of delivery. Similarly, no studies assessed the effectiveness of pharmacists compared with other health professionals providing a comparable programme, nor with pharmacy personnel other than pharmacists. We have therefore only been able to draw conclusions on the intensity of the support provided.

\section{Certainty of the evidence}

Using the GRADE criteria, we judged the evidence contributing to our primary outcome (smoking cessation) to be of low certainty. We downgraded the evidence for two reasons: 1 ) risk of bias - we rated all of the included studies at high or unclear risk of bias; 2) imprecision - fewer than 300 of the $1600+$ participants included in the meta-analysis had quit at six months follow-up or more, meaning the number of events was low.

Another potential limitation of our analysis is that because the interventions in the studies we included took place in pharmacies, where pharmacotherapy is readily available, it is difficult to tell what proportion of participants received pharmacotherapy as part of or outside of the study protocol. This difficulty is compounded by gaps in reporting for some studies, and problems with protocol adherence among pharmacy staff in other studies.

\section{Potential biases in the review process}

Cochrane methods are designed to minimise potential biases in the review process. The criteria for potential bias assessment during screening, data extraction, and analyses of the included trials strictly complied with the Cochrane Handbook for Systematic Reviews of Interventions (Higgins 2017). Two review authors independently assessed risks of bias. When conflicts arose we resolved them by discussion, with ongoing conflicts assessed using a third opinion from another review author. No conflicts of interests, financial or otherwise, were reported for any of the review authors involved in screening, extracting and interpreting data for this review. Of note, CM Bond was a principal investigators in Sinclair 1998, included in this review. However, she was not involved in the screening, data extraction or interpretation phases of this review pertaining to that study. Potentially relevant research findings may have been inadvertently missed from this review, due to presentation in forms other than peer-reviewed publications and lodgement with online clinical trial registries. However, we believe our comprehensive search strategy was sufficient to optimise identification of potentially relevant studies. Potential for selection bias was also minimised by the practice of two independent review authors screening and extracting data for potential review inclusion.

\section{Agreements and disagreements with other studies or reviews}

In line with findings observed in this review, potential benefits from community pharmacy personnel interventions have been observed in other systematic reviews investigating smoking cessation outcomes (Brown 2016; Dent 2012; Saba 2014) and other health improvement outcomes (Blenkinsopp 2003; Brown 2016). Within all these reviews there is a clear benefit of 
training pharmacists and pharmacy assistants to provide dedicated behavioural change interventions, with or without the use of pharmacological aids, to provide long-term improvements in outcomes for smokers attending these pharmacies. Although it would seem that pharmacy personnel would be an obvious choice for members of the public to obtain health advice, pharmacies are being under-used, particularly in their capacity to provide health prevention advice (Mdege 2016; Sunderland 2006). There have therefore been calls for the role of community pharmacists in public health to be investigated further (Agomo 2011). One realist review identified that few policy-relevant conclusions can be drawn from the existing evidence base due to a lack of reporting translation-relevant information, such as the use of theoretical models to underpin intervention development (Greenhalgh 2016). This is important, given concerns about the quality of services and lack of consistency in provision of information (Mdege 2016). A lack of theoretical background for health promotion to sustain the professional education of personnel has been highlighted in other studies as a factor contributing to issues of inconsistency in service quality (Nakamura 2014), while training aimed at increasing pharmacist confidence in providing services has been identified as a potential solution from multiple sources (Eades 2011; Peletidi 2016). Based on evidence from our review and others reported above, there is a clear role for community pharmacists in delivering health improvement services, particularly for smoking cessation, and the use of more intensive programmes of support may be justified.

\section{AUTHORS' CONCLUSIONS}

\section{Implications for practice}

- Pharmacists trained to provide behavioural support for smoking cessation appear to be effective in supporting smoking cessation compared with either no support or lower intensity support.

\section{Implications for research}

- Future trials of pharmacists providing behavioural support for smoking cessation are likely to enhance the certainty of the evidence and may change the conclusions of this review.

- Future studies should try to record in detail what pharmacotherapy participants received, and whether this differed between study arms.

- There was some evidence of challenges associated with studying interventions in a pharmacy setting, and future studies would benefit from concerted efforts to maintain randomisation and adherence to study protocol.

\section{ACKNOWLEDGEMENTS}

Amanda Lee provided statistical advice. Our thanks to previous authors: Hazel Sinclair and Lindsay Stead.

We would also like to thank Rachna Begh and Ali Albasri for peer review, and Sandra Wilcox for performing consumer review.

This project was supported by the National Institute for Health Research (NIHR), via Cochrane Infrastructure and Cochrane Programme Grant funding to the Cochrane Tobacco Addiction Group. The views and opinions expressed therein are those of the authors and do not necessarily reflect those of the Systematic Reviews Programme, NIHR, NHS or the Department of Health and Social Care. 


\section{REFERE N CES}

\section{References to studies included in this review}

\section{Burford 2013 \{published data only\}}

ACTRN12609000885291. Delivering a personalised smoking cessation intervention by community pharmacists in Western Australia: a pilot, randomised controlled trial. PAINT. www.anzctr.org.au/Trial/Registration/ TrialReview.aspx?id=320643 (first received 25 September 2009). [ACTRN12609000885291]

* Burford O, Jiwa M, Carter O, Parsons R, Hendrie D. Internetbased photoaging within Australian pharmacies to promote smoking cessation: randomized controlled trial. Journal of Medical Internet Research 2013;15(3):e64. []

Burford OJ. Delivering a personalised smoking cessation intervention by community pharmacists in Western Australia: A randomised controlled trial. Curtin University eSpace Institutional Repository 2012.

\section{Caponnetto 2017 \{published data only\}}

Caponnetto P, DiPiazza J, Aiello MR, Polosa R. Training pharmacists in the stage-of-change model of smoking cessation and motivational interviewing: a randomized controlled trial. Health Psychology Open 2017;0ctober:1-6. [DOI: 10.1177/2055102917736429]

\section{Dent 2009 \{published data only\}}

* Dent LA, Harris KJ, Noonan CW. Randomized trial assessing the effectiveness of a pharmacist-delivered program for smoking cessation. Annals of Pharmacotherapy 2009;43(2):194-201.

NCT00670904. Randomized trial assessing the effectiveness of a pharmacist-delivered program for smoking cessation. clinicaltrials.gov/ct2/show/NCT00670904 (first received 2 May 2008). [NCT00670904]

\section{El Hajj 2017 \{published data only\}}

El Hajj MS, Kheir N, Al Mulla AM, Al-Badriyeh D, Al Kaddour A, Mahfoud ZR, et al. Assessing the effectiveness of a pharmacistdelivered smoking cessation program in the state of Qatar: study protocol for a randomized controlled trial. Trials 2015;16:65

* El Hajj MS, Kheir N, Al Mulla AM, Shami R, Fanous N, Mahfoud ZR. Effectiveness of a pharmacist-delivered smoking cessation program in the state of Qatar: a randomized controlled trial. BMC Public Health 2017;17:215.

NCT02123329. Assessing the effectiveness of a pharmacistdelivered smoking cessation program in the state of Qatar. clinicaltrials.gov/ct2/show/NCT02123329 (first received 25 April 2014). [NCT02123329]

\section{Farley 2017 \{published data only\}}

* Farley A, Tearne S, Taskila T, Williams RH, MacAskill S, Etter J, et al. A mixed methods feasibility study of nicotine-assisted smoking reduction programmes delivered by community pharmacists - The RedPharm study. BMC Public Health 2017; 17:210.
Taskila T, MacAskill S, Coleman T, Etter J, Patel M, Clarke S, et al. A randomised trial of nicotine assisted reduction to stop in pharmacies - The RedPharm study. BMC Public Health 2012;12:182.

Maguire 2001 \{published data only\}

Maguire TA, McElnay JC, Drummond A. A randomized controlled trial of a smoking cessation intervention based in community pharmacies. Addiction 2001;96(2):325-31.

\section{Sinclair 1998 \{published data only\}}

Sinclair HK, Bond CM, Lennox AS. The longterm learning effect of training in stage of change for smoking cessation: a three year follow up of community pharmacy staff's knowledge and attitudes. International Journal of Pharmacy Practice 1999;7:1-11.

Sinclair HK, Bond CM, Lennox AS, Silcock J, Winfield AJ. An evaluation of a training workshop for pharmacists based on the Stages of Change model of smoking cessation. Health Education Journal 1997;56:296-312.

Sinclair HK, Bond CM, Lennox AS, Silcock J, Winfield AJ. Knowledge of and attitudes to smoking cessation: the effect of stage of change training for community pharmacy staff. Health Bulletin 1998;56:526-39.

* Sinclair HK, Bond CM, Lennox AS, Silcock J, Winfield AJ, Donnan PT. Training pharmacists and pharmacy assistants in the stages-of-change model of smoking cessation: a randomized controlled trial in Scotland. Tobacco Control 1998; 7(3):253-61.

Sinclair HK, Silcock J, Bond CM, Lennox AS, Winfield AJ. The cost-effectiveness of intensive pharmaceutical intervention in assisting people to stop smoking. International Journal of Pharmacy Practice 1999;7:107-12.

\section{References to studies excluded from this review}

Anderson 2002 \{published data only\}

Anderson C, Mair A. Pro-change: adult smokers program: Northumberland pilot. International Journal of Pharmacy Practice 2002;10:281-7.

Babar 2007 \{published data only\}

Babar ZU, Bukhari NI, Sarwar W, Efendie B, Pereira R, Mohamed MH. A preliminary study on the effect of pharmacist counseling on awareness of and willingness to quit smoking in Malaysian population. Pharmacy World \& Science 2007;29(3):101-3.

Baluch 1995 \{published data only\}

Baluch WM. Pharmacists role in a smoking-cessation program at a health maintenance organization. American Journal of Healthsystem Pharmacy 1995;52:287-93. 


\section{Barnes 2006 \{published data only\}}

Barnes J, Barber N, Wheatley D, Williamson EM. A pilot randomised, open, uncontrolled, clinical study of two dosages of St John's wort (Hypericum perforatum) herb extract (LI-160) as an aid to motivational/behavioural support in smoking cessation. Planta Medica 2006;72(4):378-82.

Bauld 2011 \{published data only\}

* Bauld L, Boyd KA, Briggs AH, Chesterman J, Ferguson J, Judge $K$, et al. One-year outcomes and a cost-effectiveness analysis for smokers accessing group-based and pharmacyled cessation services. Nicotine \& Tobacco Research 2011;13(2):135-45

Bauld L, Chesterman J, Ferguson J, Judge K. A comparison of the effectiveness of group-based and pharmacy-led smoking cessation treatment in Glasgow. Addiction 2009;104(2):308-16.

Boyd KA, Briggs AH. Cost-effectiveness of pharmacy and group behavioural support smoking cessation services in Glasgow. Addiction 2009;104(2):317-25.

\section{Bock 2010 \{published data only\}}

Bock BC, Hudmon KS, Christian J, Bock FR. Readiness of smokers to receive counseling for smoking cessation in a pharmacy setting. Annals of Behavioral Medicine 2008;35(Suppl. 1):S113.

* Bock BC, Hudmon KS, Christian J, Graham AL, Bock FR. A tailored intervention to support pharmacy-based counseling for smoking cessation. Nicotine \& Tobacco Research 2010;12(3):217-25.

\section{Carroll 2000 \{published data only\}}

Carroll P, Fois R, Sarson D, Flynn J. A community pharmacybased program using transdermal nicotine replacement therapy-actions and outcomes. Australian Pharmacist 2000;19(1):51-5.

\section{Condinho 2015 \{published data only\}}

Condinho M, Fernandez-Llimos F, Figueiredo IV, Sinogas C. Smoking cessation in a community pharmacy: Preliminary results of a pharmaceutical care programme. Vitae 2015;22(1):42-6.

\section{Costello 2011 \{published data only\}}

Costello MJ, Sproule B, Victor JC, Leatherdale ST, Zawertailo L, Selby P. Effectiveness of pharmacist counseling combined with nicotine replacement therapy: a pragmatic randomized trial with 6,987 smokers. Cancer Causes and Control 2011;22(2):167-80.

\section{Dent 2004 \{published data only\}}

Dent LA, Scott JG, Lewis E. Pharmacist-managed tobacco cessation program in Veterans Health Administration community-based outpatient clinic. Journal of the American Pharmacists Association (JAPha) 2004;44(6):700-14.

\section{Doescher 2002 \{published data only\}}

Doescher MP, Whinston MA, Goo A, Cummings D, Huntington J, Saver BG. Pilot study of enhanced tobacco-cessation services coverage for low-income smokers. Nicotine \& Tobacco Research 2002;4 Suppl 1:S19-S24.

Gauen 1995 \{published data only\}

Gauen SE, Lee NL. Pharmacists' role in a smoking-cessation program at a managed health-care organization. American Journal of Health-system Pharmacy 1995;52(3):294-6.

\section{Hasford 2003 \{published data only\}}

Hasford J, Fagerström KO, Haustein KO. A naturalistic cohort study on effectiveness, safety and usage pattern of an over-thecounter nicotine patch. Cohort study on smoking cessation. European Journal of Clinical Pharmacology 2003;59(5-6):443-7.

Hodges 2010 \{published data only\}

Hodges L, Gilbert H, Sutton S. Using computer-tailored smoking-cessation advice in community pharmacy: A feasibility study. International Journal of Pharmacy Practice 2010;17(6):365-8.

Hoving 2010 \{published data only\} Hoving C, Mudde AN, Dijk F, De Vries H. Effectiveness of a smoking cessation intervention in Dutch pharmacies and general practices. Health Education 2010;110(1):17-29.

Howard-Pitney 1999 \{published data only\}

Howard-Pitney B, Killen JD, Fortmann SP. Quitting chew: results from a randomized trial using nicotine patches. Experimental and Clinical Psychopharmacology 1999;7(4):362-71.

Isacson 1998 \{published data only\}

Isacson D, Bingefors C, Ribohn M. Quit smoking at the pharmacy -an evaluation of a smoking cessation programme in Sweden. Journal of Social and Administrative Pharmacy 1998;15(3):164-73.

\section{Jansen 2014 \{published data only\}}

Jansen I, Keizers S. Evaluation of a smoking cessation intervention in a community pharmacy [Evaluatie van een stoppen-met-roken-interventie in de openbare apotheek]. Pharmaceutisch Weekblad. Scientific Edition 2014;149(8):26-31. [CRS: 9400129000000757; EMBASE: 2014239471]

\section{Kennedy 2002 \{published data only\}}

Kennedy DT, Giles JT, Chang ZG, Small RE, Edwards JH. Results of a smoking cessation clinic in community pharmacy practice. Journal of the American Pharmaceutical Association 2002;42(1):51-6.

\section{Liang 2017 \{published data only\}}

Liang J, Abramson M, Zwar N, Russell G, Holland A, Bonevski B, et al. A cluster randomized trial of an interdisciplinary intervention for COPD in Australian primary care. Respirology 2018;23:42.

Liang J, Abramson M, Zwar N, Russell G, Holland A, Bonevski B, et al. Pharmacist-led smoking cessation intervention in Australian primary care targeting smokers at risk of developing COPD. Respirology 2018;23:40.

* Liang J, Abramson MJ, Zwar N, Russell G, Holland AE, Bonevski B, et al. Interdisciplinary model of care (RADICALS) 
for early detection and management of chronic obstructive pulmonary disease (COPD) in Australian primary care: study protocol for a cluster randomised controlled trial. BMJ Open 2017;7(9):e016985.

\section{Madurasinghe 2017 \{published data only\}}

Madurasinghe VW, Sohanpal R, James W, Steed L, Eldridge S, Taylor SJ, et al. Smoking treatment optimisation in pharmacies (STOP): a cluster randomised pilot trial of a training intervention. Pilot and Feasibility Studies 2017;3(1):1-11.

\section{McEwen 2006 \{published data only\}}

McEwen A, West R, McRobbie H. Effectiveness of specialist group treatment for smoking cessation vs. one-toone treatment in primary care. Addictive Behaviors 2006;31(9):1650-60.

\section{Mochizuki 2004 \{published data only\}}

Mochizuki M, Hatsugaya M, Rokujoh E, Arita E, Hashiguchi M, Shimizu N, et al. Randomized controlled study on the effectiveness of community pharmacists' advice for smoking cessation by Nicorette--evaluation at three months after initiation. Yakugaku Zasshi: Journal of the Pharmaceutical Society of Japan 2004;124:989-95.

\section{NCT02433860 \{published data only\}}

NCT02433860. Evaluation of the effectiveness of pharmacists in implementing the SCRIPT protocol. clinicaltrials.gov/ct2/show/ NCT02433860 (first received 5 May 2015). [NCT02433860]

\section{NCT02554071 \{published data only\}}

NCT02554071. Manitoba pharmacist initiated smoking cessation pilot project. clinicaltrials.gov/ct2/show/ NCT02554071 (first received 18 September 2015).

\section{NCT03518476 \{unpublished data only\}}

NCT03518476. Evaluation of an intensive education program on the treatment of tobacco use disorder for pharmacists: a randomized controlled trial. clinicaltrials.gov/ct2/show/ NCT03518476 (first received 8 May 2018).

\section{Patwardhan 2012 \{published data only\}}

Patwardhan P, Chewning B. Randomized controlled trial evaluating the effect of a multimodal training intervention on brief tobacco cessation counseling in community chain pharmacies. Journal of the American Pharmacists Association: JAPhA 2010; Vol. 50, issue 2:260. []

* Patwardhan PD, Chewning BA. Effectiveness of intervention to implement tobacco cessation counseling in community chain pharmacies. Journal of the American Pharmacists Association : JAPhA 2012;52(4):507-14. []

\section{Prokhorov 2006 \{published data only\}}

Prokhorov AV, Luca N, Marani S, Wetter D, Lovong D, Hudmon KS, et al. Training physicians and pharmacists in smoking cessation counseling: preliminary results (POS2-69). Society for Research on Nicotine and Tobacco 12th Annual Meeting February 15-18, Orlando, Florida. 2006.

\section{Prokhorov 2010 \{published data only\}}

Guglielmo BJ. A prescription for improved chronic disease management: have community pharmacists function at the top of their training: comment on "Engaging physicians and pharmacists in providing smoking cessation counseling". Archives of Internal Medicine 2010;170(18):1646-7.

* Prokhorov AV, Hudmon KS, Marani S, Foxhall L, Ford KH, Luca NS, et al. Engaging physicians and pharmacists in providing smoking cessation counseling. Archives of Internal Medicine 2010;170(18):1640-6.

Purcell 2006 \{published data only\}

Purcell JL, Farris KB, Aquillo ML. Feasibility of a brief smoking cessation intervention in community pharmacies. Journal of the American Pharmacy Association 2006;46(5):616-8.

Roth 2001 \{published data only\}

Roth MT, Westman EC. Use of bupropion SR in a pharmacistmanaged outpatient smoking-cessation program. Pharmacotherapy 2001;21(5):636-41.

\section{Sonderskov 1997 \{published data only\}}

Sonderskov J, Olsen J, Meillier L, Overvad OK, Sabroe S. The effect of transdermal nicotine patches in smoking cessation. A randomized trial in pharmacy customers in Denmark [Effekten af transdermalt nikotinplaster ved rygeafvaenning. En randomiseret undersogelse blandt apotekskunder i Danmark]. Ugeskrift for laeger 1999;161(5):593-7.

* Sonderskov J, Olsen J, Sabroe S, Meillier L, Overvad K. Nicotine patches in smoking cessation: A randomized trial among over- the-counter customers in Denmark. American Journal of Epidemiology 1997;145(4):309-18.

Swartz 1995 \{published data only\}

Swartz SH, Ellsworth AJ, Curry SJ, Boyko EJ. Community patterns of transdermal nicotine use and provider counseling. Journal of General Internal Medicine 1995;10(12):656-62.

\section{UMIN000029545 \{published data only\}}

UMIN000029545. A pharmacist-delivered smoking cessation program in community pharmacy: A feasibility study. upload.umin.ac.jp/cgi-open-bin/ctr_e/ctr_view.cgi? recptno=R000033626 (first received 13 October 2017).

Vial 2002 \{published data only\}

Vial RJ, Jones TE, Ruffin RE, Gilbert AL. Smoking cessation program using nicotine patches linking hospital to the community. Journal of Pharmacy Practice and Research 2002;32(1):57-62.

\section{Vitale 2000 \{published data only\}}

Vitale F. Professional intervention for smoking cessation: The contribution of the pharmacist. European Journal of Public Health 2000;10(3 Suppl):21-4

\section{Wongwiwatthananukit 2010 \{published data only\}}

Wongwiwatthananukit S, Dumrongpiwat S, Krittiyanunt S, Dhummaupakorn R, Suwanmajo S. Development and evaluation of pharmacist-based smoking cessation program 
for youth offenders. Journal of the American Pharmacists Association : JAPhA 2010; Vol. 50, issue 2:267-8. []

\section{References to ongoing studies}

ISRCTN16351033 \{published data only\}

ISRCTN16351033. A training and service intervention to optimise pharmacist-based treatment for smoking cessation. www.isrctn.com/ISRCTN16351033 (first received 26 March 2018).

\section{Thomas 2013 \{published data only\}}

Thomas D, Abramson MJ, Bonevski B, Taylor S, Poole S, Weeks GR, et al. A pharmacist-led system-change smoking cessation intervention for smokers admitted to Australian public hospitals (GIVE UP FOR GOOD): study protocol for a randomised controlled trial. Trials 2013;14:148. []

\section{Zillich 2013 \{published data only\}}

Corelli RL, Zillich AJ, De Moor C, Giuliano MR, Arnold J, Fenlon CM, et al. Recruitment of community pharmacies in a randomized trial to generate patient referrals to the tobacco quitline. Research in Social \& Administrative Pharmacy 2013;9(4):396-404. [CENTRAL: 985080; CRS: 9400129000000426 ; PUBMED: 22841641]

* Zillich AJ, Corelli RL, Zbikowski SM, Magnusson LB, Fenlon CM, Prokhorov AV, et al. A randomized trial evaluating 2 approaches for promoting pharmacy-based referrals to the tobacco quitline: Methods and baseline findings. Research in Social \& Administrative Pharmacy: RSAP 2013;9(1):27-36. []

\section{Additional references}

\section{Agomo 2011}

Agomo CO. The role of community pharmacists in public health: a scoping review of the literature. Journal of Pharmaceutical Health Serivces Research 2011;3(1):25-33.

\section{Agomo 2018}

Agomo C, Udoh A, Kpokiri E, Osuku-Opio J. Community pharmacists' contribution to public health: assessing the global evidence base. Clinical Pharmacist 2018; Vol. article number 20204556.

\section{Blenkinsopp 2003}

Blenkinsopp A, Anderson C, Armstrong M. Systematic review of the effectiveness of community pharmacy-based interventions to reduce risk behaviours and risk factors for coronary heart disease. Journal of Public Health Medicine 2003;25(2):144-53.

\section{Boutwell 2014}

Boutwell L, Cook L, Norman K, Lindsey WT. A pharmacist's guide for smoking cessation. Alabama Pharmacy Association 2014. [0178-000-14-101-H04-P ]

\section{Brown 2014}

Brown D, Portlock J, Rutter P, Nazar Z. From community pharmacy to healthy living pharmacy: Positive early experiences from Portsmouth, England. Research in Social and Administrative Pharmacy 2014;10(1):72-87.

\section{Brown 2016}

Brown TJ, Todd A, O'Malley C, Moore HJ, Husband AK, Bambra $\mathrm{C}$, et al. Community pharmacy-delivered interventions for public health priorities: a systematic review of interventions for alcohol reduction, smoking cessation and weight management, including meta-analysis for smoking cessation. BMJ Open 2016;6(2):e009818.

\section{Cantor 2015}

Cantor SB, Deshmukh AA, Luca NS, Nogueras-González GM, Rajan T, Prokhorov AV. Cost-effectiveness analysis of smokingcessation counseling training for physicians and pharmacists. Addictive Behaviors 2015;45:79-86.

\section{Collins 2008}

Collins D, Lapsley H. The costs of tobacco, alcohol and illicit drug abuse to Australian society in 2004/2005. Commonwealth of Australia. Canberra: Commonwealth of Australia, 2008; Vol. Publication number P3-2625. [ISBN 1-74186-436-4]

\section{Commonwealth of Australia 2018}

Commonwealth of Australia. Australian government response to the review of pharmacy remuneration and regulation. Commonwealth of Australia, Department of Health 2018; Vol. Publication Number 12185. [ISBN: 978-1-76007-357-2 ]

\section{Csikar 2015}

Csikar JI, Douglas GV, Pavitt S, Hulme C. The cost-effectiveness of smoking cessation services provided by general dental practice, general medical practice, pharmacy and NHS Stop Smoking Services in the North of England. Community Dentistry and Oral Epidemiology 2015;44(2):119-27.

\section{Dent 2012}

Dent LA, Harris KJ, Noonan CW. Tobacco interventions delivered by pharmacists: A summary and systematic review. Pharmacotherapy 2012;27(7):1040-51.

\section{Eades 2011}

Eades CE, Ferguson JS, O'Carroll RE. Public health in community pharmacy: A systematic review of pharmacist and consumer views. BMC Public Health 2011;11(582):1-13.

\section{Greenhalgh 2016}

Greenhalgh T, Macfarlane F, Steed L, Walton R. What works for whom in pharmacist-led smoking cessation support: realist review. BMC Medicine 2016;14(209):1-16.

\section{Hartmann-Boyce 2019}

Hartmann-Boyce J, Hong B, Livingstone-Banks J, Wheat H, Fanshawe TR. Additional behavioural support as an adjunct to pharmacotherapy for smoking cessation. Cochrane Database of Systematic Reviews 2019, Issue 6. [DOI: 10.1002/14651858.CD009670.pub4]

\section{Higgins 2017}

Higgins JP, Altman DG, Sterne JA, (editors). Chapter 8: Assessing risk of bias in included studies. In: Higgins JP, Churchill R, 
Chandler J, Cumpston MS, (editors), Cochrane Handbook for Systematic Reviews of Interventions version 5.2.0 (updated June 2017), The Cochrane Collaboration, 2017. Available from www.training.cochrane.org/handbook.

\section{Higgins 2019}

Higgins JP, Thomas J, Chandler J, Cumpston M, Li T, Page MJ, Welch VA (editors). Cochrane Handbook for Systematic Reviews of Interventions version 6.0 (updated July 2019). The Cochrane Collaboration, 2019. Available from www.training.cochrane.org/ handbook.

\section{Hollands 2019}

Hollands GJ, Naughton F, Farley A, Lindson N, Aveyard P. Interventions to increase adherence to medications for tobacco dependence. Cochrane Database of Systematic Reviews 2019, Issue 8. [DOI: 10.1002/14651858.CD009164.pub3]

\section{Hudmon 2003}

Hudmon KS, Hemberger KK, Corelli RL, Kroon LA, Prokhorov AV. The pharmacist's role in smoking cessation counseling: perceptions of users of nonprescription nicotine replacement therapy. Journal of the American Pharmacists Association (JAPha) 2003;43(5):573-82.

\section{Hudmon 2004}

Hudmon KS, Kroon LA, Corelli RL, Saunders KC, Spitz MR, Bates TR, et al. Training future pharmacists at a minority educational institution: evaluation of the Rx for change tobacco cessation training program. Cancer Epidemiology, Biomarkers \& Prevention 2004;13(3):477-81.

\section{Hudmon 2005}

Hudmon KS, Bardel K, Kroon LA, Fenlon CM, Corelli RL. Tobacco education in U.S. schools of pharmacy. Nicotine \& Tobacco Research 2005;7(2):225-32.

\section{Maguire 1995}

Maguire T. Smoking cessation: a model service for UK community pharmacists. International Journal of Smoking Cessation 1995;4:18-21.

\section{Maguire 1996}

Maguire T. Pharmaceutical care - a realistic pharmaceutical service. Pharmacy Today 1996;7:20-4.

\section{Maguire 1997}

Maguire T. Smoking cessation, nicotine replacement therapy and community pharmacy. Pharmaceutical Journal 1997;258:239-40.

\section{McMillan 2014}

McMillan SS, Kelly F, Sav A, King MA, Whitty JA, Wheeler AJ. Australian community pharmacy services: a survey of what people with chronic conditions and their carers use versus what they consider important. BMJ Open 2014;4(12):e006587.

\section{Mdege 2016}

Mdege ND, Chevo T, Toner P. Perceptions of current and potential public health involvement of pharmacists in developing nations: The case of Zimbabwe. Research in Social and Administrative Pharmacy 2016;12(6):876-84.

\section{Nakamura 2014}

Nakamura CA, Soares L, Farias MR, Leite SN. Pharmaceutical services and health promotion: how far have we gone and how are we faring? Scientific output in pharmaceutical studies. Brazilian Journal of Pharmaceutical Sciences 2014;50(4):773-82.

\section{Peletidi 2016}

Peletidi A, Nabhani-Gebara S, Kayyali R. Smoking cessation support services at community pharmacies in the UK: A systematic review. Hellenic Journal of Cardiology 2016;57:7-15.

\section{Public Health England 2017}

Public Health England. Pharmacy: A way forward for public health. assets.publishing.service.gov.uk/government/uploads/ system/uploads/attachment_data/file/643520/Pharmacy_a_ way_forward_for_public_health.pdf 2017; Vol. 2017212.

\section{Rooney 1996}

Rooney BL, Murray DM. A meta-analysis of smoking prevention programs after adjustment for errors in the unit of analysis. Health Education Quarterly 1996;23(1):48-64.

\section{Saba 2014}

Saba M, Diep J, Saini B, Dhippayom T. Meta-analysis of the effectiveness of smoking cessation interventions in community pharmacy. Journal of Clinical Pharmacy and Therapeutics 2014;39(3):240-7.

\section{Schünemann 2017}

Schünemann HJ, Oxman AD, Higgins JPT, Vist GE, Glasziou P, Akl E, Guyatt GH on behalf of the Cochrane GRADEing Methods Group and the Cochrane Statistical Methods Group. Chapter 11: Completing 'Summary of findings' tables and grading the confidence in or quality of the evidence. In: Higgins JP, Churchill R, Chandler J, Cumpston MS, (editors), Cochrane Handbook for Systematic Reviews of Interventions version 5.2.0 (updated June 2017). The Cochrane Collaboration, 2017. Available from www.training.cochrane.org/handbook..

\section{Sunderland 2006}

Sunderland B, Burrows S, Joyce A, McManus A, Maycock B. Rural pharmacy not delivering on its health promotion potential. Australian Journal of Rural Health 2006;14(3):116-9.

\section{Tran 2002}

Tran MT, Holdford DA, Kennedy DT, Small RE. Modeling the costeffectiveness of a smoking-cessation program in a community pharmacy practice. Pharmacotherapy 2002;22:1623-31.

\section{USDHHS 2014}

U.S. Department of Health and Human Services. The health consequences of smoking - 50 years of progress: A report of the Surgeon General: Executive Summary. Centers for Disease Control and Prevention, National Center for Chronic Disease Prevention and Health Promotion, Office on Smoking and Health 2014. 


\section{Veterans Health Administration 2000}

Veterans Health Administration, Montana Regional Healthcare System. Vets without cigarettes smoking cessation program. Veterans Health Adminstration 2000.

\section{West 2000}

West R, McNeill A, Raw M. Smoking cessation guidelines for health professionals: an update. Thorax 2000;55(12):987-99.

\section{West 2015}

West R, Raw M, McNeill A, Stead L, Aveyard P, Bitton J, et al. Health-care interventions to promote and assist tobacco cessation: a review of efficacy, effectiveness and affordability for use in national guideline development. Addiction 2015;110(9):1388-403.

\section{WHO 1994}

World Health Organization. The role of the pharmacist in the health care system. apps.who.int/medicinedocs/en/d/ Jh2995e/1.6.2.html 1994; Vol. WHO/PHARM/94.569.

\section{WHO 2015}

World Health Organization. WHO global report on trends in prevalence of tobacco smoking 2015. apps.who.int/

\section{CHARACTERISTICS OF STUDIES}

Characteristics of included studies [ordered by study ID] iris/bitstream/handle/10665/156262/9789241564922 eng.pdf;jsessionid=03D8996D633CBB72272E4D81DCA56846? sequence=1 2015. [ISBN: 9789241564922 ]

\section{Zillich 2002}

Zillich AJ, Ryan M, Adams A, Yeager B, Farris K. Effectiveness of a pharmacist-based smoking-cessation program and its impact on quality of life. Pharmacotherapy 2002;22(6):759-65.

\section{References to other published versions of this review Sinclair 2002}

Sinclair HK, Bond CM. Community pharmacy personnel interventions for smoking cessation. Cochrane Database of Systematic Reviews 2002, Issue 2. [DOI: 10.1002/14651858.CD003698]

\section{Sinclair 2004}

Sinclair HK, Bond CM, Stead LF. Community pharmacy personnel interventions for smoking cessation. Cochrane Database of Systematic Reviews 2004, Issue 1. [DOI: 10.1002/14651858.CD003698.pub2]

* Indicates the major publication for the study

\section{Burford 2013}

\section{Methods} Country: Australia

Design: Randomised controlled trial

Study objective: To conduct a randomised controlled trial of a computer-generated photo-aging intervention to promote smoking cessation among young adult smokers within a community pharmacy setting

Method of analysis: Logistic regression model, random-effects regression model, incremental cost-effectiveness ratio

Clustering adjustments made: Not applicable

Eligible for study: 213
Randomised: Intervention $\mathrm{n}=80 ;$ Control $\mathrm{n}=80$
Completed: Intervention $\mathrm{n}=59$; Control $\mathrm{n}=63$
Age: Intervention 24.2; Control 25.1
Gender: Men $\mathrm{n}=60 ;$ Women $\mathrm{n}=100$
Inclusion criteria: Smokers aged 18 to 30, presenting at pharmacy to collect prescribed or OTC medica-
tions
Exclusion criteria: Already using NRT, bearded, body dysmorphic


Burford 2013 (Continued)

Intervention description: Faces of participants were photographed and their images were digitally aged as both a smoker and a nonsmoker (using internet-based APRIL Face Ageing software; a 3D age progression software, creating aged images of faces using algorithms based on reference data). Participants were invited to view the age-processed images. Although the intervention did not include pharmacotherapy, participants were recruited when they presented to pharmacy to collect prescribed or OTC medications

Control description: Standard 2-minute smoking cessation advice from the pharmacist

Duration of intervention: 2-minute smoking cessation advice

\begin{tabular}{|c|c|c|}
\hline Outcomes & \multicolumn{2}{|c|}{$\begin{array}{l}\text { Prespecified outcomes: Successful quitting, quit attempts, and progression along transtheoretical } \\
\text { stages-of-change model. Cost effectiveness of intervention (incremental cost per additional quitter and } \\
\text { per additional lifetime quitter) } \\
\text { Follow-up period: } 6 \text { months }\end{array}$} \\
\hline Notes & \multicolumn{2}{|c|}{$\begin{array}{l}\text { Funding: none reported } \\
\text { Declarations of interest: none declared. }\end{array}$} \\
\hline \multicolumn{3}{|l|}{ Risk of bias } \\
\hline Bias & Authors' judgement & Support for judgement \\
\hline $\begin{array}{l}\text { Random sequence genera- } \\
\text { tion (selection bias) }\end{array}$ & High risk & $\begin{array}{l}\text { Allocation performed based on pharmacy attendance in alternating weeks. } \\
\text { Quote: "Allocation into the groups alternated weekly so that all participants } \\
\text { recruited in any specific week received the same treatment" }\end{array}$ \\
\hline $\begin{array}{l}\text { Allocation concealment } \\
\text { (selection bias) }\end{array}$ & High risk & No mention of concealment, but unlikely to be concealed, as not blinded \\
\hline $\begin{array}{l}\text { Incomplete outcome data } \\
\text { (attrition bias) } \\
\text { All outcomes }\end{array}$ & Low risk & $\begin{array}{l}\text { Attrition ( }<50 \% \text { overall) similar between groups (intervention: } 17 / 80 \text {, control }= \\
21 / 80 \text { ) }\end{array}$ \\
\hline $\begin{array}{l}\text { Blinding of outcome as- } \\
\text { sessment (detection bias) } \\
\text { All outcomes }\end{array}$ & Low risk & $\begin{array}{l}\text { The researcher collecting the data was not blinded to group allocation. Bio- } \\
\text { chemical verification of abstinence was carried out and there were similar } \\
\text { amounts of contact in the intervention and control arms }\end{array}$ \\
\hline $\begin{array}{l}\text { Selective reporting (re- } \\
\text { porting bias) }\end{array}$ & Low risk & $\begin{array}{l}\text { All outcomes planned in the protocol and Methods section reported on in the } \\
\text { Results }\end{array}$ \\
\hline
\end{tabular}

\section{Caponnetto 2017}

Country: Italy
Design: Cluster-randomised controlled trial
Study objective: To evaluate the effect of the training on smoking cessation outcomes and to help par-
ticipants (pharmacists) develop an understanding of the key principles of the stage-of change model
and MI approach
Method of analysis: Descriptive statistics (i.e. frequencies/percentages, means/standard deviations)
used to describe the intervention content (active vs control group); Smoking cessation rates reported
and cessation rates analysed using the Fisher test; ITT analysis used in the context of analysis of vari-
ance (ANOVA) the Wilcoxon/Mann-Whitney test applied assuming that all those smokers who were lost
to follow-up were classified as failures




Eligible for study: $\mathrm{n}=46$ pharmacies
Randomised: $\mathrm{n}=42$ pharmacies; $\mathrm{n}=187$ participants (Intervention $\mathrm{n}=124 ;$ Control $\mathrm{n}=63$ )
Completed: $\mathrm{n}=21$ pharmacies; Participant numbers not reported; assume same numbers with lost-to-
follow-up reported as smoking
Age: not reported
Gender: not reported
Inclusion criteria: all smokers who sought advice on smoking cessation or those who bought an OTC an-
ti-smoking product in preparation for a new attempt to stop smoking were eligible for inclusion
Exclusion criteria: not reported

Interventions

Setting: Training conducted by Centro per la Prevenzione e Cura del Tabagismo at the University of Catania. During the recruitment period, all smokers who sought advice on smoking cessation or those who bought an OTC anti-smoking product in preparation for a new attempt were recruited from the pharmacy

Intervention description: Same as control, plus an additional 6-hour training session; Smokers were informed that their pharmacists were trained in specific anti-smoking counselling based on stage-ofchange and MI theories; Intervention personnel offered their customers the professional anti-smoking counselling; pharmacy staff maintained a confidential participant record which documented their progress in smoking cessation, any product supplied, points raised by the participant, and advice given. At each of the planned follow-up visits, telephone call reminders were carried out to improve participation; Intervention pharmacotherapy was not provided as standard practice but could be provided if requested

Control description: Control group pharmacists attended a 3-hour conference training session based on the US Public Health Services 2008 Clinical Practice Guidelines for Treating Tobacco Use and Dependence, and aligned with the principles of MI and the stage-of-change model. Smokers were informed that their pharmacists recently attended a conference on "Clinical Practice Guidelines for Treating Tobacco Use and Dependence"; The control group asked customers to register and then continued to provide standard professional support; Pharmacy staff maintained a confidential participant record which documented their progress in smoking cessation, any product supplied, points raised by the participant, and advice given; at each of the planned follow-up visits, telephone call reminders were carried out to improve participation

Duration of intervention: Not specified

Outcomes Prespecified outcomes: Number of treated smokers, smoking reduction at 24 weeks with validation through exhaled $\mathrm{CO}$

Follow-up period: 24 weeks

Notes Funding: "The author(s) received no financial support for the research, authorship, and/or publication of this article."

Declarations of interest: "The author(s) declared no potential conflicts of interest with respect to the research, authorship and/or publication of this article."

\section{Risk of bias}

\begin{tabular}{lll}
\hline Bias & Authors' judgement & Support for judgement \\
\hline $\begin{array}{l}\text { Random sequence genera- } \\
\text { tion (selection bias) }\end{array}$ & Unclear risk & $\begin{array}{l}\text { Quote "Successively, pharmacies were randomly allocated, by sequential allo- } \\
\text { cation, to the intervention or control group" }\end{array}$ \\
\hline
\end{tabular}


Caponnetto 2017 (Continued)

\begin{tabular}{lll}
$\begin{array}{l}\text { Allocation concealment } \\
\text { (selection bias) }\end{array}$ & Unclear risk & Not reported \\
\hline $\begin{array}{l}\text { Incomplete outcome data } \\
\text { (attrition bias) } \\
\text { All outcomes }\end{array}$ & High risk & $\begin{array}{l}\text { Significant loss of study clusters: only 13/21 intervention pharmacies and } 8 / 21 \\
\text { control pharmacies completed the study. Participant follow-up rates not re- } \\
\text { ported }\end{array}$
\end{tabular}

\begin{tabular}{|c|c|c|}
\hline $\begin{array}{l}\text { Blinding of outcome as- } \\
\text { sessment (detection bias) } \\
\text { All outcomes }\end{array}$ & Low risk & Abstinence biochemically validated \\
\hline $\begin{array}{l}\text { Selective reporting (re- } \\
\text { porting bias) }\end{array}$ & Unclear risk & $\begin{array}{l}\text { No published protocol available; outcomes reported in the Methods were re- } \\
\text { ported in analyses }\end{array}$ \\
\hline
\end{tabular}

\section{Dent 2009}

Methods
Designtry: USA
Study objective: To assess the effectiveness on smoking cessation of a face-to-face group programme
conducted by the pharmacist team compared with a brief standard-care session delivered by a phar-
macist over the telephone
Method of analysis: Participant data and testing results were recorded in a Microsoft SQL Server 2000
database. Baseline categorical variables by intervention group were compared using the Chi2 test and
the 2-sample t-test
Clustering adjustments made: Not applicable

Eligible for study: $\mathrm{n}=120$
Randomised: $\mathrm{n}=101$
Completed: Intervention $\mathrm{n}=49 ;$ Control $\mathrm{n}=48$
Age: Intervention $56.7 ;$ Control 55.0
Gender: Men $93 \%$
Inclusion criteria: daily tobacco users for 7 days or more motivated to quit smoking
Exclusion criteria: Had recently started NRT

Interventions

Setting: Single outpatient pharmacy department in the Rocky Mountain region of the USA

Intervention description: Motivational programme delivered in $3 \times 2$-hour sessions in small groups by pharmacists using the transtheoretical model of change and health belief model. Specifically consisted of peer support, goal setting, behavioural strategies and cognitive strategies tailored to individual's current motivation to quit. Follow-up support was provided as necessary in person or over the phone. NRT and bupropion were offered as appropriate

Control description: Participants received 1 timed 5- to 10-minute session over the phone that included all the components of standard care recommended by the Clinical Practice Guidelines and practiced within the VA for brief interventions delivered by healthcare providers, referred to as "The 5 A's". NRT and bupropion were offered as appropriate

Duration of Intervention: 3 in-person sessions ( 3 hours for session 1, 2 hours for session 2 and 1 hour for session 3) delivered at 2-week intervals over 5 weeks 
Dent 2009 (Continued)

Outcomes Prespecified outcomes: 7-day, 30-day and continuous abstinence rates, self-reported by participants at 6 months following the intervention

Follow-up period: 6 months

$\begin{array}{ll}\text { Notes } & \text { Funding: The Prevent Cancer Foundation } \\ & \text { Declarations of interest: not reported }\end{array}$

\title{
Risk of bias
}

\begin{tabular}{|c|c|c|}
\hline Bias & Authors' judgement & Support for judgement \\
\hline $\begin{array}{l}\text { Random sequence genera- } \\
\text { tion (selection bias) }\end{array}$ & Low risk & $\begin{array}{l}\text { Quote: "Randomization codes assigned to each participant were computer } \\
\text { generated by the study statistician and stratified by sex in blocks of } 6 . "\end{array}$ \\
\hline $\begin{array}{l}\text { Allocation concealment } \\
\text { (selection bias) }\end{array}$ & Unclear risk & $\begin{array}{l}\text { No mention of whether or how allocation was concealed: } \\
\text { Quote: "The pharmacist team conducted a baseline assessment over the tele- } \\
\text { phone, then notified participants of their group assignment." }\end{array}$ \\
\hline $\begin{array}{l}\text { Incomplete outcome data } \\
\text { (attrition bias) } \\
\text { All outcomes }\end{array}$ & Low risk & $\begin{array}{l}\text { Attrition rates low and similar between groups (1/51 lost to intervention, } 3 / 51 \\
\text { lost to control) }\end{array}$ \\
\hline $\begin{array}{l}\text { Blinding of outcome as- } \\
\text { sessment (detection bias) } \\
\text { All outcomes }\end{array}$ & Low risk & Abstinence biochemically verified using urinary cotinine \\
\hline $\begin{array}{l}\text { Selective reporting (re- } \\
\text { porting bias) }\end{array}$ & Unclear risk & $\begin{array}{l}\text { No published protocol available. Outcomes reported in the Methods were re- } \\
\text { ported in analyses }\end{array}$ \\
\hline
\end{tabular}

El Hajj 2017

Country: Qatar
Design: Prospective cluster- randomised controlled trial
Study objective: To test the effect of a structured smoking cessation programme delivered by trained
pharmacists on smoking cessation rates in Qatar
Method of analysis: Chi2 test, independent t-test
Clustering adjustments made: The main analysis did not change when adjusted for the possible cluster-
ing effect by the pharmacists

\section{Participants}

\author{
Eligible for study: 361 \\ Randomised: Intervention $\mathrm{n}=167 ;$ Control $\mathrm{n}=147$ \\ Completed: Intervention $n=68 ;$ Control $n=68$
}

Age: Intervention $32.5 \%$ aged 30 to 39 ; Control $38.7 \%$ aged 30 to 39

Gender: Men $\mathrm{n}=307 ;$ Women $\mathrm{n}=54$

Inclusion criteria: Smokers 18 years and older who smoked one or more cigarettes daily, were able to communicate in Arabic or English, and who were motivated to quit 
Intervention description: Smokers assigned to the intervention group participated in a face-to-face 4session programme at the pharmacy by the study pharmacist at 2- to 4-week intervals over 8 weeks. NRT was provided

Control description: Participants in the control group received 5 to 10 minutes of unstructured one-toone brief smoking cessation counselling by the pharmacist emulating current practice. NRT was offered

Duration of intervention: 4 sessions over 8 weeks

\begin{tabular}{ll}
\hline Outcomes & $\begin{array}{l}\text { Prespecified outcomes: Self-reported 7-day point prevalence abstinence, self-reported 30-day point } \\
\text { prevalence abstinence, self-reported continuous abstinence defined as having smoked no cigarettes } \\
\text { since quit day - validated by exhaled CO levels }\end{array}$ \\
Follow-up period: 3,6 and 12 months
\end{tabular}

\section{Risk of bias}

\begin{tabular}{|c|c|c|}
\hline Bias & Authors' judgement & Support for judgement \\
\hline $\begin{array}{l}\text { Random sequence genera- } \\
\text { tion (selection bias) }\end{array}$ & Low risk & $\begin{array}{l}\text { Quote: "The [randomization] sequences were generated by the study statisti- } \\
\text { cian using a computer program from the website randomization.com" }\end{array}$ \\
\hline $\begin{array}{l}\text { Allocation concealment } \\
\text { (selection bias) }\end{array}$ & Low risk & $\begin{array}{l}\text { Quote: "Serially numbered, opaque, sealed randomization envelopes were } \\
\text { then provided to each study pharmacist." }\end{array}$ \\
\hline $\begin{array}{l}\text { Incomplete outcome data } \\
\text { (attrition bias) } \\
\text { All outcomes }\end{array}$ & Low risk & $\begin{array}{l}\text { Follow-up rates less than } 50 \% \text { overall and similar between groups ( } 68 / 167 \text { of } \\
\text { intervention, } 68 / 147 \text { of control participants completed all } 3 \text { follow-ups) }\end{array}$ \\
\hline $\begin{array}{l}\text { Blinding of outcome as- } \\
\text { sessment (detection bias) } \\
\text { All outcomes }\end{array}$ & Low risk & $\begin{array}{l}\text { Quote: "at } 12 \text { months, participants who self-reported not smoking were invit- } \\
\text { ed to come to their study clinic to measure their exhaled CO level by the clinic } \\
\text { nurse who was blinded to the participants' group." } \\
\text { Comment: Only } 8 / 35 \text { participants self-reporting abstinence attended and the } \\
\text { amount of face-to-face contact differed between groups }\end{array}$ \\
\hline $\begin{array}{l}\text { Selective reporting (re- } \\
\text { porting bias) }\end{array}$ & Low risk & $\begin{array}{l}\text { Protocol available. All outcomes of interest to this review reported as planned. } \\
\text { All outcomes planned in the Methods section reported on in the Results }\end{array}$ \\
\hline Other bias & Unclear risk & $\begin{array}{l}\text { Authors report that it is plausible that the pharmacists, who were overall ex- } \\
\text { tremely motivated and enthusiastic, might have inadvertently contaminat- } \\
\text { ed the usual-care group with extra care. This may have increased the smoking } \\
\text { cessation rates in this group. } \\
\text { It was unclear whether the NRT offered in study arms was matched. The word- } \\
\text { ing suggested that the NRT may have been provided in the intervention arm } \\
\text { and only offered in the control arm. However, this uncertainty could just be } \\
\text { the result of the terms used rather than an actual difference in practice }\end{array}$ \\
\hline
\end{tabular}


Farley 2017

Methods
Design: Randomised controlled trial
Study objective: To investigate the feasibility of implementing a smoking reduction programme in com-
munity pharmacies, when compared to self-help methods
Method of analysis: Relative risks and risk differences, generalised linear mixed model. t-test to com-
pare continuous outcomes
Clustering adjustments made: Not applicable

Pligible for study: 70
Randomised: Intervention $\mathrm{n}=36$; Control $\mathrm{n}=32$
Age: Intervention $44 ;$ Control 44
Gender: Men $\mathrm{n}=34 ;$ Women $\mathrm{n}=34$
Inclusion criteria: Smokers aged 18 and over who were not planning to quit within the next 4 weeks but
wanted to reduce consumption

Exclusion criteria: currently using pharmacological, behavioural or alternative therapies for smoking cessation, pregnancy, severe medical or psychiatric conditions

$2 \times 2$ factorial trial in which participants received either behavioural support or self-help, and were encouraged to reduce their smoking either over 4 weeks or over 16 weeks. We consider only the support/self-help comparison, and include both reduction times in each study arm

Intervention description: Pharmacists provided behavioural support to promote smoking cessation; suggesting that learning a new pattern of smoking would prevent consumption increasing again by disrupting learnt associations between cues and smoking behaviour. They encouraged participants to use NRT and choose 1 of 3 methods of reduction

Control description: In the control arm, the smoking reduction methods were exactly the same as above, but they were explained in a written booklet. We asked pharmacists to hand out the booklets without further advice or interaction

Duration of intervention: 8 visits

Pharmacotherapy: Participants in both study arms were prescribed NRT, and encouraged to take it for 9 months, regardless of intention to reduce or stop, or failure of either reduction or cessation.

\author{
Outcomes Prespecified outcomes: Biochemically confirmed prolonged abstinence measured at 6 months \\ Follow-up period: 6 months
}

Notes
Funding: "The trial was funded by the National Prevention Research Initiative of the UK, administered by the MRC. The funding partners are Alzheimer's Research UK, Alzheimer's Society, Biotechnology and Biological Sciences Research Council, British Heart Foundation, Cancer Research UK, Chief Scientist Of- fice, Scottish Government Health Directorate, Department of Health, Diabetes UK, Economic and So- cial Research Council, Engineering and Physical Sciences Research Council, Health and Social Care Re- search Division, Public Health Agency, Northern Ireland, Medical Research Council, Stroke Association, Wellcome Trust, Welsh Government, and World Cancer Research Fund."

Declarations of interest: "The authors declare that they have no competing interests." 
Farley 2017 (Continued)

Risk of bias

\begin{tabular}{|c|c|c|}
\hline Bias & Authors' judgement & Support for judgement \\
\hline $\begin{array}{l}\text { Random sequence genera- } \\
\text { tion (selection bias) }\end{array}$ & Low risk & $\begin{array}{l}\text { Quote: "The research team generated the randomisation sequence using a } \\
\text { computer algorithm at http://www.randomization.com" }\end{array}$ \\
\hline $\begin{array}{l}\text { Allocation concealment } \\
\text { (selection bias) }\end{array}$ & Unclear risk & $\begin{array}{l}\text { Allocations given to pharmacists in numbered, sealed envelopes, but unclear if } \\
\text { sequentially numbered and opaque }\end{array}$ \\
\hline \multirow[t]{2}{*}{$\begin{array}{l}\text { Incomplete outcome data } \\
\text { (attrition bias) } \\
\text { All outcomes }\end{array}$} & High risk & $\begin{array}{l}\text { Quote: "The percentage of participants successfully contacted each month } \\
\text { fell steadily in all trial arms, with 18, } 24,26 \text { and } 13 \% \text { being followed up at } 12 \\
\text { months in the behavioural/standard, self-help/standard, behavioural/short } \\
\text { and self-help/short groups respectively" }\end{array}$ \\
\hline & & Comment: Dropout differed across study arms \\
\hline $\begin{array}{l}\text { Blinding of outcome as- } \\
\text { sessment (detection bias) } \\
\text { All outcomes }\end{array}$ & Low risk & 6-month abstinence biochemically verified \\
\hline $\begin{array}{l}\text { Selective reporting (re- } \\
\text { porting bias) }\end{array}$ & Low risk & $\begin{array}{l}\text { All outcomes planned in the protocol and Methods section reported on in the } \\
\text { Results }\end{array}$ \\
\hline \multirow[t]{3}{*}{ Other bias } & High risk & $\begin{array}{l}\text { Authors report that there was evidence that pharmacists did not follow ran- } \\
\text { domisation protocols, as they strongly believed that their support was essen- } \\
\text { tial to participants in the control arm. }\end{array}$ \\
\hline & & $\begin{array}{l}\text { Quote: "Participants randomised to the self-help conditions should not have } \\
\text { received behavioural support when returning to collect further NRT prescrip- } \\
\text { tions. However, there was evidence that pharmacists were routinely recording } \\
\text { reduction targets, setting new reduction targets, and less commonly record- } \\
\text { ing reduction methods used in the self-help participants, suggesting that they } \\
\text { were in fact providing support" }\end{array}$ \\
\hline & & $\begin{array}{l}\text { Quote: "There was evidence that pharmacists did not follow randomisation } \\
\text { protocols... In both cases of duplicate enrolment, pharmacists opened a sec- } \\
\text { ond envelope in order to offer behavioural support." }\end{array}$ \\
\hline
\end{tabular}

Maguire 2001

$\begin{array}{ll}\text { Methods } & \text { Country: United Kingdom } \\ \text { Design: Randomised controlled trial }\end{array}$

Study objective: To evaluate whether a structured community pharmacy-based smoking cessation programme (the PAS model) would produce a higher smoking cessation rate compared with ad hoc advice from pharmacists

Method of analysis: Clustering of data from tape recordings were analysed through the Gestault method to focus on similar key themes and concepts and to examine how they were related to variables within the same population

Clustering adjustments made: Not applicable

Pligible for study: Smokers $n=484$ (Pharmacies $n=51)$
Randomised: Intervention $n=265 ;$ Control $n=219$


Maguire 2001 (Continued)

Completed: Intervention $n=38(14.3 \%) ;$ Control $n=6(2.7 \%)$

Age: Intervention 42; Control 38

Gender: Men $\mathrm{n}=281 ;$ Women $\mathrm{n}=203$

Inclusion criteria: Smokers expressing a wish to stop smoking, > 18 years, not pregnant, no minimum cigarettes/day

Interventions

Setting: One-to-one counselling interventions were carried out in community pharmacies in Northern Ireland and in London, England

3-hour training workshop for pharmacists plus 1 support visit to each pharmacist. The workshop covered epidemiology, smoking statistics, NRT use, cycle of change model and Pharmacists' Action on Smoking (PAS) model

Intervention description: The PAS intervention involved a structured counselling programme, information leaflet and record keeping. They were required to attend a weekly follow-up for the first 4 weeks then monthly for 3 months as needed. NRT was offered if appropriate

Control description: Unstructured brief advice. The normal pharmaceutical service was provided by the pharmacist (including an offer of NRT if appropriate). Participants were not counselled using the PAS resources, were not given the PAS information leaflet and were not asked to attend follow-up interviews. Demographic details were collected from this group

Duration of intervention: Pharmacy follow-up advice weekly for 4 weeks, then monthly for 3 months

$\begin{array}{ll}\text { Outcomes } & \begin{array}{l}\text { Prespecified outcomes: Smoking status or self-reported continuous abstinence at 3, } 6 \text { and } 12 \text { months } \\ \text { and positive and negative aspects of experiences during smoking cessation study } \\ \text { Follow-up period: } 12 \text { months }\end{array} \\ \text { Notes } & \begin{array}{l}\text { Pharmacists paid GBP } 15 \text { per smoker enrolled and followed up for } 12 \text { months. No recruit attended for } \\ \text { counselling after } 4 \text { weeks }\end{array} \\ \text { Funding: the Medical Research Council and the N. Ireland Department of Health and Social Services } \\ \text { Declarations of interest: not reported }\end{array}$

\section{Risk of bias}

\begin{tabular}{lll}
\hline Bias & Authors' judgement & Support for judgement \\
\hline $\begin{array}{l}\text { Random sequence genera- } \\
\text { tion (selection bias) }\end{array}$ & Unclear risk & $\begin{array}{l}\text { Quote: "Randomization was achieved using a sealed envelope technique (Alt- } \\
\text { man \& Gore, 1982). The randomization envelopes were provided to each site } \\
\text { for the use of one pharmacist only" }\end{array}$ \\
& Comment: No further information provided
\end{tabular}

\begin{tabular}{|c|c|c|}
\hline $\begin{array}{l}\text { Allocation concealment } \\
\text { (selection bias) }\end{array}$ & Unclear risk & $\begin{array}{l}\text { Quote: "Randomization was achieved using a sealed envelope technique (Alt- } \\
\text { man \& Gore, 1982). The randomization envelopes were provided to each site } \\
\text { for the use of one pharmacist only" } \\
\text { Comment: Not specified if opaque }\end{array}$ \\
\hline $\begin{array}{l}\text { Incomplete outcome data } \\
\text { (attrition bias) } \\
\text { All outcomes }\end{array}$ & Low risk & $\begin{array}{l}\text { Loss to follow-up reported for both groups at 3-month follow-up ( } 10.2 \% \\
(27 / 265) \text { of the PAS group; } 14.2 \%(31 / 219) \text { of the non-PAS group). Loss to fol- } \\
\text { low-up was reported to stay the same at } 6 \text { - and } 12 \text {-month follow-up }\end{array}$ \\
\hline
\end{tabular}

Blinding of outcome as- Low risk $\quad$ Abstinence was biochemically verified using urinary cotinine


Maguire 2001 (Continued)

All outcomes

Selective reporting (reporting bias)
Unclear risk

No published protocol available. All outcomes planned in the Methods section report on in the Results

\section{Sinclair 1998}

Methods

Country: United Kingdom

Design: Cluster-randomised controlled trial of community pharmacies and pharmacy customers

Study objective: To evaluate a training workshop for community pharmacy personnel to improve their counselling in smoking cessation based on the stage-of-change model

Method of analysis: Multiple logistic regression

Clustering adjustments made: "The estimates of intra-cluster correlation $(\mathrm{p})$ for the outcomes at each time point were calculated". The effects of clustering were negligible

\section{Participants}

Eligible for study: Pharmacies $\mathrm{n}=76$ (775 patients)

Randomised: Pharmacies $n=62$ (Patients: Intervention $n=224$; Control $n=268$ )

Completed: Pharmacies: Intervention $n=31$; Control $n=29$ (Patients: Intervention $n=159$; Control $n=$ 188)

Age: Intervention 41.7; Control 41.5

Gender: Men $\mathrm{n}=185 ;$ Women $\mathrm{n}=302$

Inclusion criteria: Pharmacy customers seeking advice on stopping smoking or buying an OTC anti-smoking product in preparation for a new attempt to stop smoking; Recruitment period 12 months; No limit to number of recruits per pharmacy

Intervention description: 2-hour training workshop for pharmacists and pharmacy assistants: based on stages-of-change model and communication skills for negotiating change and providing ongoing support; no focus on smoking cessation products. Trained pharmacy staff offered participants the Pharmacy Support Programme which involved participant registration, counselling and ongoing record keeping at each subsequent purchase of OTC medications

Control description: Usual care, mandated by UK law as a minimum of the display of health education material

Duration of intervention: "Brief", exact time not specified

Outcomes

Prespecified outcomes: Self-reported point prevalence of smoking at 1 month and continuous abstinence at 4 and 9 months; Age, gender, postcode (proxy for socioeconomic status), nicotine dependence (Fagerström test) recorded at 1 month post-intervention; Consumer response to structured questionnaire assessing perception of the support package at 4 months

Follow-up period: 1, 4 and 9 months

Self-reported point prevalence at 1 month, continuous abstinence at 4 and 9 months

Notes

No additional pharmacy reimbursement. Evaluated effects of clustering by calculating ICCs for each outcome; concluded no evidence of significant cluster effect

Funding: The Scottish Office, Department of Health 
Sinclair 1998 (Continued)

Declarations of interest: not stated

\section{Risk of bias}

\begin{tabular}{lll}
\hline Bias & Authors' judgement & Support for judgement \\
\hline $\begin{array}{l}\text { Random sequence genera- } \\
\text { tion (selection bias) }\end{array}$ & Unclear risk & No details of randomisation methods \\
\hline $\begin{array}{l}\text { Allocation concealment } \\
\text { (selection bias) }\end{array}$ & Unclear risk & No information on allocation concealment methods \\
\hline $\begin{array}{l}\text { Incomplete outcome data } \\
\text { (attrition bias) } \\
\text { All outcomes }\end{array}$ & Low risk & $\begin{array}{l}\text { Quote: "Nine-month smoking data were provided by a total of 73.2\% (347) of } \\
\text { the recruited customers: 73.3\% (159) intervention and 73.2\% (188) controls" }\end{array}$ \\
\hline $\begin{array}{l}\text { Blinding of outcome as- } \\
\text { sessment (detection bias) }\end{array}$ & Unclear risk & $\begin{array}{l}\text { Abstinence not biochemically validated } \\
\text { All outcomes }\end{array}$ \\
$\begin{array}{l}\text { Quote: "Intervention personnel offered their customers the Pharmacy Support } \\
\text { Programme, which involved client registration, counselling, and record keep- } \\
\text { ing. The control group asked customers to register and then continued to pro- } \\
\text { vide standard professional support." }\end{array}$ \\
$\begin{array}{l}\text { Comment: Based on this description it is not clear if different amounts of face- } \\
\text { to-face contact were provided }\end{array}$ \\
\hline $\begin{array}{l}\text { Selective reporting (re- } \\
\text { porting bias) }\end{array}$ & $\begin{array}{l}\text { Unclear risk } \\
\text { in the Results }\end{array}$ \\
\hline
\end{tabular}

CO: carbon monoxide; ICC: intra-class correlation coefficient; ITT: intention-to-treat; MI: motivational interviewing; OTC: over the counter;

Characteristics of excluded studies [ordered by study ID]

\begin{tabular}{|c|c|}
\hline Study & Reason for exclusion \\
\hline Anderson 2002 & Feasibility study; No 6-month follow-up; No comparators \\
\hline Babar 2007 & No control group \\
\hline Baluch 1995 & No control group \\
\hline Barnes 2006 & No control group. All participants received pharmacist support and St John's Wort \\
\hline Bauld 2011 & Observational study comparing group-based support to one-on-one counselling, not random \\
\hline Bock 2010 & $\begin{array}{l}\text { RCT comparing electronically-delivered smoking cessation programme alone compared with a } \\
\text { smoking cessation programme plus NRT with observational no-intervention arm, not random }\end{array}$ \\
\hline Carroll 2000 & No control group \\
\hline Condinho 2015 & No control group \\
\hline Costello 2011 & RCT of 2 behavioural interventions; 1 with NRT and 1 without; No control group, 5 -week follow-up \\
\hline Dent 2004 & No control group \\
\hline
\end{tabular}




\begin{tabular}{|c|c|}
\hline Study & Reason for exclusion \\
\hline Doescher 2002 & No control group \\
\hline Gauen 1995 & No control group \\
\hline Hasford 2003 & No control group (evaluated OTC nicotine patch) \\
\hline Hodges 2010 & No control group; Follow-up less than 6 months after the intervention \\
\hline Hoving 2010 & Intervention was not delivered by pharmacy personnel \\
\hline Howard-Pitney 1999 & Randomised to receive NRT or placebo; both groups received same behavioural treatment \\
\hline Isacson 1998 & No control group \\
\hline Jansen 2014 & No control group \\
\hline Kennedy 2002 & No control group \\
\hline Liang 2017 & $\begin{array}{l}\text { Intervention took place in a primary care setting and incorporates different types of primary care } \\
\text { staff }\end{array}$ \\
\hline Madurasinghe 2017 & Less than 6 months follow-up \\
\hline McEwen 2006 & $\begin{array}{l}\text { Non-randomised study with 4-week follow-up. Some individual counselling participants were } \\
\text { treated by pharmacists }\end{array}$ \\
\hline Mochizuki 2004 & Randomised study with only 3 months follow-up (pilot study, 28 participants) \\
\hline NCT02433860 & Not community pharmacy clients \\
\hline NCT02554071 & No control group \\
\hline NCT03518476 & Participants not community pharmacy clients \\
\hline Patwardhan 2012 & Feasibility study, no smoking cessation outcomes \\
\hline Prokhorov 2006 & $\begin{array}{l}\text { Study of pharmacist and physician training with 3-month follow-up, smoking cessation outcomes } \\
\text { not reported in abstract }\end{array}$ \\
\hline Prokhorov 2010 & $\begin{array}{l}\text { Study of pharmacist and physician training with } 12 \text {-month follow-up, smoking cessation outcomes } \\
\text { not reported }\end{array}$ \\
\hline Purcell 2006 & No control group; Follow-up less than 6 months after the intervention \\
\hline Roth 2001 & No control group \\
\hline Sonderskov 1997 & NRT versus placebo, no other intervention \\
\hline Swartz 1995 & No control group \\
\hline UMIN000029545 & Follow-up 3 months only \\
\hline Vial 2002 & $\begin{array}{l}\text { Participants did not meet the criteria for consideration in this review, i.e. were not community } \\
\text { pharmacy clients who were smokers wishing to stop. Participants recruited in a hospital setting } \\
\text { and randomised to } 1 \text { of } 3 \text { arms of the study; support programme of counselling and nicotine patch- } \\
\text { es initiated in hospital with the first consultation with a research pharmacist common to } 2 \text { groups, }\end{array}$ \\
\hline
\end{tabular}




\begin{tabular}{ll}
\hline Study & Reason for exclusion \\
\hline & $\begin{array}{l}\text { then continued by hospital- or community pharmacy-based pharmacists compared with minimal } \\
\text { intervention without nicotine patches }\end{array}$ \\
\hline Vitale 2000 & Descriptive paper, no control group \\
\hline Wongwiwatthananukit 2010 & Not community pharmacy clients \\
\hline
\end{tabular}

OTC: over the counter; NRT: nicotine replacement therapy

Characteristics of ongoing studies [ordered by study ID]

\section{ISRCTN16351033}

\begin{tabular}{ll}
\hline Trial name or title & STOP study \\
\hline Methods & Country: United Kingdom \\
Design: Cluster-randomised controlled trial \\
Study objective: To test whether a service improvement and training programme (called the STOP \\
intervention) for pharmacy staff will improve the uptake and reduce dropouts in the National \\
Health Service (NHS) Stop Smoking Programme and improve quit rates \\
Method of analysis: Not reported \\
Clustering adjustments made: Community pharmacists (the cluster level) will be randomised; no \\
mention of adjustments for clustering, though number of smokers attending a treatment session \\
and setting a quit date is the primary outcome
\end{tabular}

Participants Intended to randomise: $\mathrm{n}=60$ pharmacies with 1320 smokers

Age: 18 and over to be recruited

Gender: Not reported

Inclusion criteria: Current smokers aged 18 and above; All types of smoking (cigarettes, cigar, pipe)

Exclusion criteria: For community pharmacies and pharmacy staff: 1 . Sites that lack the facilities for secure storage and transfer of the study data; 2 . Advisors who refuse GCP training;

Exclusion criteria for service users who will be part of the study exploring individual participant-level outcomes: 1 . Non-smokers; 2 . Unable to understand the STOP study service user information sheet and consent form; 3 . Unable/unwilling to give written informed consent for STOP study additional data collection procedures for detailed analysis

Intervention description: STOP intervention - "based on behavioural theory involving training for pharmacy staff and associated study materials (e.g. badges, posters). The intervention training focuses on team approach in delivering the NHS STOP smoking service. "

Control description: "The National Centre for Smoking Cessation and Training (NCSCT) offers a range of training, assessment and certification programmes for both clinical and non-clinical health and social care workers to become more skilled in smoking cessation. Control pharmacies will only receive NCSCT training (Level 1 or Level 2 depending on staff experience)."

Duration of intervention: At least 1 stop-smoking session with a community pharmacist, but it is unclear if there are additional sessions 
ISRCTN16351033 (Continued)

Outcomes
Prespecified outcomes: Primary outcome: number of smokers who join the NHS Stop Smoking Program (SSP), attend a treatment session and set a firm date (i.e. a treated smoker);

Secondary outcomes: 4-week retention rate, defined as proportion of treated smokers retained at 4 weeks; 4-week quit rate, defined as proportion of smokers who quit smoking at 4 weeks from set quit date, i.e. a "carbon monoxide (CO)-verified 4-week quitter"; Continuous abstinence rate, defined as proportion of smokers who quit at 4 weeks (CO-verified) and remained so at 6 months; Effect of the training intervention on additional (routine) data provided by the consented service users; Additional process outcomes include: Satisfaction about the NHS SSP by questionnaire; Selfefficacy in smoking cessation delivery by questionnaire; Study recruitment and retention rates of pharmacies and pharmacy staff, reasons for non-participation and dropout, service user consent/recruitment rates for additional data collection and retention rates; Intervention training attendance and completion rates, reasons for non-attendance and dropout; Acceptability of intervention training and delivery in practice by questionnaire; Delivery of skills in practice at the pharmacy counter around engagement of service users into the NHS SSP by simulated client using checklist; Skills around retention of service users in pharmacy consultation room by audio-recording of consultations; Views and experiences about the STOP training and its delivery in practice; Views and experiences about the NHS SSP with a focus on engagement and retention, reasons for completion and non-completion of the NHS SSP; Health economic outcomes included: Cost data from advisers: time spent (in minutes) by advisers on smoker service user delivering the NHS SSP and taking individual consent for STOP study additional data collection procedures and carrying out the data collection, e.g. saliva samples; Cost data from study researchers: cost of delivery of training to pharmacy staff and costs associated with delivery of training such as travel expenses, refreshments, room hire, use of printed materials, use of assistive technology; provision of financial incentive; attending feedback meeting with trainer

Follow-up period: 4-week quit rates and 6 months continuous abstinence

\begin{tabular}{|c|c|}
\hline Starting date & May 2017 to August 2019 \\
\hline Contact information & $\begin{array}{l}\text { Ms Wai Yee James; STOP Trial Manager; Blizard Institute; Yvonne Carter Building; } 58 \text { Turner Street, } \\
\text { London, E1 2AB; United Kingdom }\end{array}$ \\
\hline \multirow[t]{3}{*}{ Notes } & $\begin{array}{l}\text { Funding: National Institute for Health Research (NIHR) Central Commissioning Facility (CCF); Grant } \\
\text { Codes: RP-PG-0609-10181 }\end{array}$ \\
\hline & Study registration: ISRCTN16351033 \\
\hline & Declarations of interest: none stated \\
\hline
\end{tabular}

\section{Thomas 2013}

\section{Trial name or title}

Methods
Country: Australia

Design: Randomised controlled trial, multicentre, single-blinded

Study objective: The primary aim of the study is to determine the effectiveness of a pharmacist-led system change intervention ('GIVE UP FOR GOOD') compared to usual care on biochemically verified 7-day point prevalence abstinence at 6 months and 12 months

Method of analysis: Characteristics of study participants will be compared using the $\mathrm{Chi}^{2}$ test for categorical variables and the Student's t-test or a non-parametric equivalent for continuous and discrete variables; Multivariable analysis will be used to compare outcomes between the 2 treatment groups while adjusting for prognostic variables and potential confounders; All the statistical tests will be interpreted with a significance level of 5\% (2-tailed); Data will be analysed according to ITT principles; all randomised participants will be included in the analysis and those lost to fol- 
low-up will be regarded as smokers; Participants who die during the study will be excluded from the analysis

Clustering adjustments made: None reported

\section{Participants}

Intended to randomise: $\mathrm{n}=300$ per arm $(\mathrm{n}=600$ in total $)$

Age: 18 years or older

Gender: Not specifically reported

Inclusion criteria: Inpatients 18 years old or older, are smokers at the time of hospital admission, and are available for follow-up on discharge, and up to 12 months post-discharge

Exclusion criteria: Physical or mental inability to participate in the study, inability to provide written informed consent, inability to communicate in English, terminal illness, pregnancy or on another active smoking cessation therapy or programme at the time of hospital admission (pharmacotherapy including NRT or active involvement in a smoking cessation programme in the last 7 days prior to the hospital admission with support from a trained counsellor, health professional or service provider)

Intervention description: Smoking cessation support sessions with a trained pharmacist; The conceptual framework for the intervention is based on the systems change approach, which has 6 systems-level strategies to facilitate treatment of tobacco dependence:

1. Implement a system of identifying smokers;

2. Provide education and resources to promote provider intervention;

3. Dedicate staff to provide smoking cessation services;

4. Promote hospital policies that support and provide tobacco dependence services;

5. Include tobacco dependence treatments (both counselling and pharmacotherapies) identified as effective; and

6. Reimburse healthcare providers for delivery of effective tobacco dependence treatments and include these services among their defined duties.

Control description: Participants randomised to the usual care (control) group will continue to receive routine care provided by the hospital. They may receive brief counselling by hospital staff and/or free NRT or pharmacotherapy during their hospital stay as per hospital policy

Duration of intervention: The intervention will be delivered over at least 3 sessions, with the final session taking place within 1 month after hospital discharge

Outcomes

Prespecified outcomes: The primary aim of the study is to determine the effectiveness of a pharmacist-led system change intervention ('GIVE UP FOR GOOD') compared to usual care on biochemically-verified 7-day point prevalence abstinence at 6 months and 12 months; The secondary objectives are: 1 . To evaluate the effectiveness of the 'GIVE UP FOR GOOD' intervention compared to usual care on self-reported continuous abstinence at discharge and at 1, 6 and 12 months post-discharge; 2 . To evaluate the effectiveness of the 'GIVE UP FOR GOOD' intervention compared to usual care on self-reported 24-hour, 7-day and 30-day point prevalence abstinence at 1, 6 and 12 months post-discharge

Follow-up period: 1,6 and 12 months

Starting date 
Thomas 2013 (Continued)

Contact information

Dennis Thomas: Centre for Medicine Use and Safety, Faculty of Pharmacy and Pharmaceutical Sciences, Monash University (Parkville Campus), 381 Royal Parade, Parkville, VIC, 3052, Australia; Dennis.Thomas@monash.edu

Notes

Funding: "This trial is funded by the Australian Research Council through the Linkage Scheme (LP110200724) and an investigator-initiated research (IIR) grant from Pfizer. BB is supported by a Cancer Institute NSW Career Development Fellowship."

Declarations of interest: "The study is supported by an investigator initiated research (IIR) grant from Pfizer. However, Pfizer was not involved in the design of the study, protocol development or implementation and will not be involved in the analysis and publication of findings. Recommendations for pharmacotherapy will be evidence-based and according to guidelines based on a participant's nicotine dependence and participant preference. Professor Abramson was a member of the Scientific Committee for a workshop on an unrelated topic that was sponsored by GlaxoSmithKline, but did not receive any honorarium"

Zillich 2013

Trial name or title

Methods

Country: USA (Connecticut and Washington)

Design: Randomised controlled trial

Study objective: The study aims to estimate and compare the effectiveness of 2 interventions (academic detailing and mailed materials) for engaging community pharmacy personnel (pharmacists and pharmacy technicians) in applying the Ask-Advise-Refer method to generate referrals to the tobacco quitline

Method of analysis: The monthly numbers and percentages of quitline calls from callers who report hearing about the quitline from a pharmacy between the baseline and 12-month follow-up will be tested for statistical significance using generalised linear regression modelling with the numbers and percentages regressed on study period and state (Connecticut or Washington); The number of quitline callers who register for cessation counselling, the total number of quitline cards distributed, and the number of calls per 100 cards distributed at each pharmacy will be compared and analysed at the pharmacy level; comparisons between study conditions will be made using generalised linear regression models with the outcome regressed on the study condition variable, state, and pharmacy type

Clustering adjustments made: None reported

Participants Intended to randomise: $\mathrm{n}=32$ pharmacies for each arm ( $\mathrm{n}=64$ pharmacies in total)

Age: Not specified

Gender: Not specified

Inclusion criteria: Licensed pharmacies were identified from a list obtained from the Connecticut and Washington State Boards of Pharmacy

Exclusion criteria: Pharmacies that were not community-based (e.g. not hospital, mail order, or clinic-based pharmacies)

Intervention description: Both mailed (control) and academic detailing interventions advocated for implementation of the Ask-Advise-Referstrategy; academic detailing interventions were provided on-site by an experienced pharmacist; the detailer assessed current cessation activities, determined knowledge of quitlines, and identified barriers and/or facilitators to cessation-related activ- 
ities; videos were used to demonstrate the Ask-Advise-Refer model for tobacco cessation; The other intervention materials were selectively introduced, at the detailer's discretion, to facilitate incorporation of Ask-Advise-Refer into routine pharmacy practice; The detailer concluded the session by answering questions and offering to assist with placement of the materials in the pharmacy

Control description: Mailed paper-based quitline materials (videos not included)

Duration of intervention: 1 training session

Outcomes

Prespecified outcomes: The primary study outcomes include (1) between-group comparisons of the total number of quitline registrants referred from the 64 study pharmacies during the intervention period and (2) changes in the number of quitline registrants referred from all pharmacies in Connecticut and Washington during the baseline monitoring period versus the intervention period; Secondary outcomes include (1) the number of quitline cards and brochures distributed to participants (assessed by on-site card and brochure counts by study personnel at 3 and 6 months) and (2) changes in self-reported cessation counselling and referral behaviour (measured by written surveys completed by participating pharmacists and pharmacy technicians at baseline, 3 months, and 6 months)

Follow-up period: 3 and 6 months

Starting date macy, 1001 W. 10th Street - W7555 Myers, Indianapolis, IN 46202, USA; Department of Clinical Pharmacy, University of California, 521 Parnassus Ave, C-152, Box 0622, San Francisco, CA 94143, USA: khudmon@purdue.edu; Tel.: +1 317613 2315x311; fax: +1 3176132316

Notes

Funding: "Funded by the National Cancer Institute grant R01 CA 129312 to K Hudmon. A portion of Dr. Zillich's time was supported by a Career Development award RCD 06-304-1 from the Department of Veterans Affairs, Health Services Research and Development."

Declarations of interest: not reported

ITT: intention-to-treat; NRT: nicotine replacement therapy

\section{DATA AND ANALYSES}

Comparison 1. More versus less intensive SC support

\begin{tabular}{lllll}
\hline Outcome or subgroup title & No. of studies & $\begin{array}{l}\text { No. of partici- } \\
\text { pants }\end{array}$ & Statistical method & Effect size \\
\hline 1 Smoking cessation & 6 & 1614 & Risk Ratio (M-H, Random, 95\% Cl) & $2.30[1.33,3.97]$ \\
\hline
\end{tabular}

Analysis 1.1. Comparison 1 More versus less intensive SC support, Outcome 1 Smoking cessation.

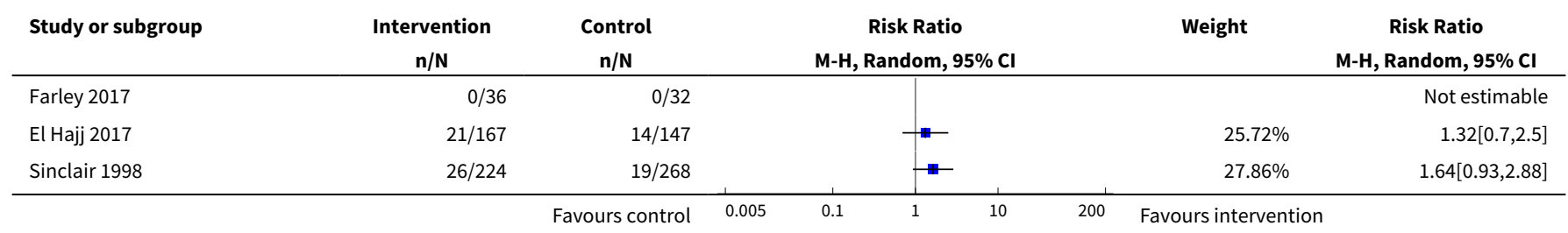




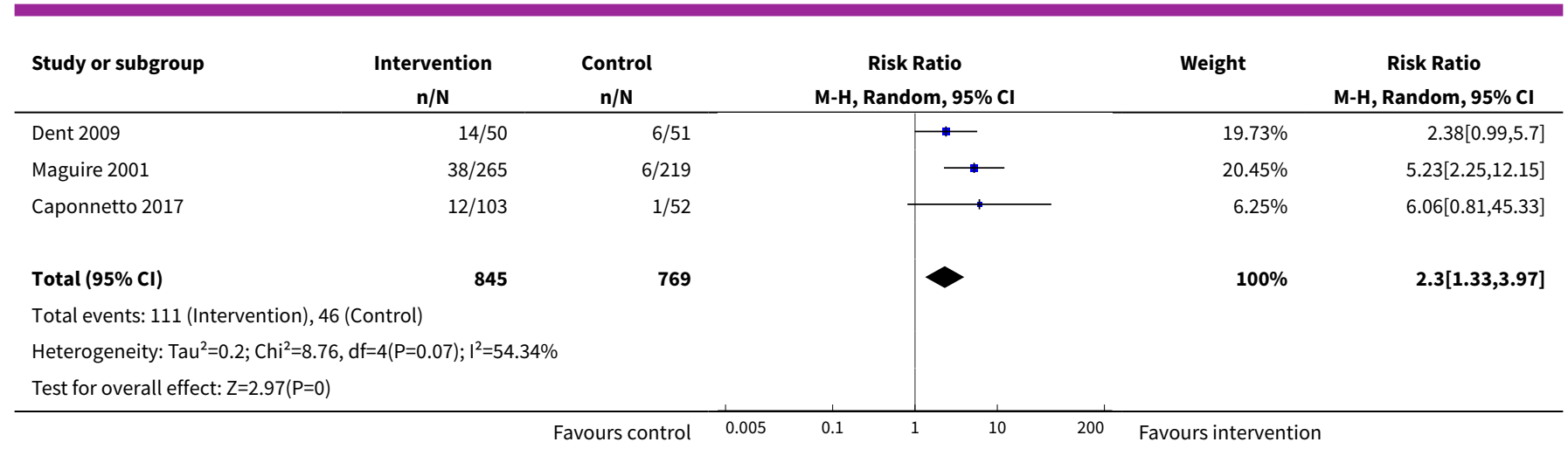

Comparison 2. Face-aging + brief advice versus brief advice alone

\begin{tabular}{lllll}
\hline Outcome or subgroup title & No. of studies & $\begin{array}{l}\text { No. of partici- } \\
\text { pants }\end{array}$ & Statistical method & Effect size \\
\hline 1 Smoking cessation & 1 & & Risk Ratio (M-H, Random, $95 \% \mathrm{Cl})$ & Subtotals only \\
\hline
\end{tabular}

Analysis 2.1. Comparison 2 Face-aging + brief advice versus brief advice alone, Outcome 1 Smoking cessation.

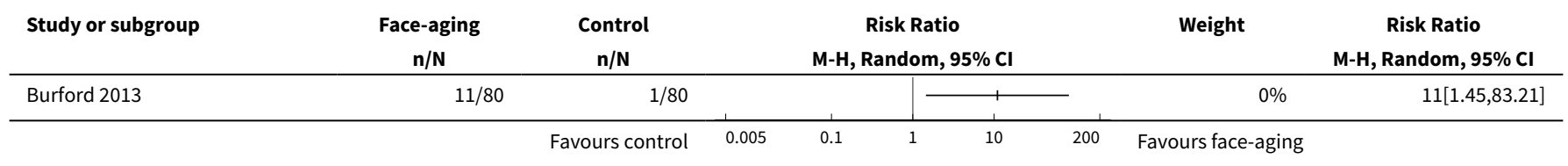

\section{APPENDICES}

\section{Appendix 1. Cochrane register search strategy}

\#1 (pharmacy OR pharmacies OR pharmacist*):TI,AB

\#2 (pharmacy OR pharmacies OR pharmacist):MH

\#3 (pharmacy OR pharmacies OR pharmacist):EMT

\#4 (pharmacy OR pharmacies OR pharmacist):KW,KY

\#5 (pharmacy OR pharmacies OR pharmacist*):XKY

\#6 \#1 OR \#2 OR \#3 OR \#4 OR \#5

\section{Appendix 2. Online clinical trial registry search strategy}

Pharmacy AND smoking cessation

\section{WHAT'S NEW}




\begin{tabular}{lll}
\hline Date & Event & Description \\
\hline 11 January 2019 & New search has been performed & Searches updated \\
\hline 15 October 2018 & $\begin{array}{l}\text { New citation required and conclusions } \\
\text { have changed }\end{array}$ & $\begin{array}{l}7 \text { new studies included, risks of bias updated, 'Summary of find- } \\
\text { ings' table added, text of review updated }\end{array}$ \\
\hline
\end{tabular}

\section{HISTORY}

Protocol first published: Issue 3, 2002

Review first published: Issue 1, 2004

\begin{tabular}{lll}
\hline Date & Event & Description \\
\hline 18 June 2008 & Amended & Converted to new review format. \\
\hline 31 October 2007 & New search has been performed & $\begin{array}{l}\text { Search update for Issue 1, 2008. No new studies included. New } \\
\text { references added to the Excluded studies and Background. }\end{array}$ \\
\hline
\end{tabular}

\section{CONTRIBUTIONS OF AUTHORS}

For this update, KVCC and JLB screened studies for inclusion, extracted data, and updated the analyses and text. MB, ZK, RT and KS searched the updated literature and extracted data. All authors approved the final text.

\section{DECLARATIONS OF INTEREST}

KVCC: none known.

JLB: none known.

KS: none known.

ZK: none known.

MP: none known.

RT: none known.

CM Bond was a principal investigator in the (Sinclair 1998) study included in this review.

\section{SOURCES OF SUPPORT}

\section{Internal sources}

- University of Aberdeen, UK.

- Nuffield Department of Primary Care Health Sciences, University of Oxford, UK.

\section{External sources}

- NIHR Cochrane Infrastructure Grant, UK.

- NIHR Cochrane Programme Grant, UK.

\section{DifFERENCES BETWEEN PROTOCOL AND REVIEW}

We added adverse effects as a primary outcome, in line with Cochrane guidelines. We also added cost effectiveness as a secondary outcome.

We conducted meta-analysis using the random-effects model because of expected heterogeneity between studies, in line with updated practice for the Cochrane Tobacco Addiction Group. We added sensitivity analyses removing studies where the provision of pharmacotherapy potentially differed between study arms. 
INDEX TERMS

\section{Medical Subject Headings (MeSH)}

*Pharmacies; *Pharmacists; *Smoking Cessation; Counseling; Health Promotion; Randomized Controlled Trials as Topic

\section{MeSH check words}

Humans 